\title{
Stock Market Efficiency and Economic Efficiency: Is There a Connection?
}

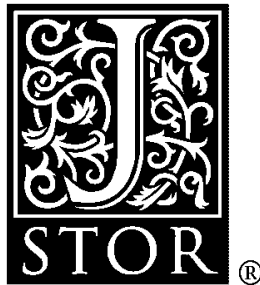

\author{
James Dow; Gary Gorton
}

The Journal of Finance, Vol. 52, No. 3, Papers and Proceedings Fifty-Seventh Annual Meeting, American Finance Association, New Orleans, Louisiana January 4-6, 1997. (Jul., 1997), pp. 1087-1129.

Stable URL:

http://links.jstor.org/sici?sici=0022-1082\%28199707\%2952\%3A3\%3C1087\%3ASMEAEE\%3E2.0.CO\%3B2-\%23

The Journal of Finance is currently published by American Finance Association.

Your use of the JSTOR archive indicates your acceptance of JSTOR's Terms and Conditions of Use, available at http://www.jstor.org/about/terms.html. JSTOR's Terms and Conditions of Use provides, in part, that unless you have obtained prior permission, you may not download an entire issue of a journal or multiple copies of articles, and you may use content in the JSTOR archive only for your personal, non-commercial use.

Please contact the publisher regarding any further use of this work. Publisher contact information may be obtained at http://www.jstor.org/journals/afina.html.

Each copy of any part of a JSTOR transmission must contain the same copyright notice that appears on the screen or printed page of such transmission.

The JSTOR Archive is a trusted digital repository providing for long-term preservation and access to leading academic journals and scholarly literature from around the world. The Archive is supported by libraries, scholarly societies, publishers, and foundations. It is an initiative of JSTOR, a not-for-profit organization with a mission to help the scholarly community take advantage of advances in technology. For more information regarding JSTOR, please contact support@jstor.org. 


\title{
Stock Market Efficiency and Economic Efficiency: Is There a Connection?
}

\author{
JAMES DOW and GARY GORTON*
}

\begin{abstract}
In a capitalist economy, prices serve to equilibrate supply and demand for goods and services, continually changing to reallocate resources to their most efficient uses. However, secondary stock market prices, often viewed as the most "informationally efficient" prices in the economy, have no direct role in the allocation of equity capital since managers have discretion in determining the level of investment. What is the link between stock price informational efficiency and economic efficiency? We present a model of the stock market in which: (i) managers have discretion in making investments and must be given the right incentives; and (ii) stock market traders may have important information that managers do not have about the value of prospective investment opportunities. In equilibrium, information in stock prices will guide investment decisions because managers will be compensated based on informative stock prices in the future. The stock market indirectly guides investment by transferring two kinds of information: information about investment opportunities and information about managers' past decisions. However, because this role is only indirect, the link between price efficiency and economic efficiency is tenuous. We show that stock price efficiency is not sufficient for economic efficiency by showing that the model may have another equilibrium in which prices are strong-form efficient, but investment decisions are suboptimal. We also suggest that stock market efficiency is not necessary for investment efficiency by considering a banking system that can serve as an alternative institution for the efficient allocation of investment resources.
\end{abstract}

IN A CAPITALIST SOCIETY, prices for goods and service play the central role in resource allocation. The strength of capitalism lies in its ability to make these prices reflect essential information so that resources are deployed efficiently. Consider a fishmonger whose prices for different kinds of fish change every day in response to availability. These prices have a direct effect on the behavior of customers entering the shop: if the price is high they may choose to eat beef for dinner instead. In other words, the allocation of fish to the most efficient uses (in this case, to the people with the highest marginal utility of fish consumption) is accomplished by price changes. These price changes directly regulate the use of the fish. Now consider the equity capital market and its relation to the allocation of funds for capital investment. If a company's share price goes

* Dow is from the European University Institute and is also affiliated with the London Business School. Gorton is from the Wharton School of the University of Pennsylvania and is a research associate at the NBER. We thank seminar participants at Princeton, UCLA, Boston College, Duke, Stanford, Northwestern, Temple, the CEPR Conference on Financial Intermediation, and London Business School for comments. 
up, it is not obvious whether its access to equity capital will be altered. This is because stock prices differ from prices in the fish market and most other markets in two ways.

First, in the case of the fishmonger, the consumer decides how much fish to buy. In contrast, decisions about the allocation of investment capital are generally delegated to managers with little or no ownership stake in the firm. Managers decide dividend policy, leverage, the timing of new issues of seasoned equity and other securities, and therefore they have discretion over the amount of funding available for investing in new assets. Although the equityholders supply the capital to the firm, they do not decide directly how much capital to supply: instead, the managers do. This is somewhat analogous to the fishmonger telling his customers how much fish to buy.

The stock market price is a secondary market price: it values the entire firm rather than a marginal investment. The role played by the stock price is the same as in the fish market example only in the simple case where a newly organized firm issues equity for the first time to fund its investment. In this special case, there is no managerial discretion: if investors believe that the capital can be more efficiently deployed elsewhere, or if the expected returns on the project are insufficient to induce enough saving, then the price will be low and the project may not be undertaken. However only an insignificant fraction of investment capital is raised in this way: the vast majority of investment is funded by retained earnings, by seasoned equity issues, or by new non-equity external financing such as bank loans or bonds.

The second difference between fish prices and secondary stock prices is that the flow of information in a stock market may be bidirectional: the market may want to learn about the quality of the managers's decisions, but the manager may also want to learn the market's valuation of prospective investments. The stock price, although intrinsically irrelevant to the investment decision, may be useful indirectly because it conveys information about prospective investment projects and cash flows. For example, a high stock price may signal to the manager that the market believes that the firm has profitable investment opportunities. The fact that the manager seeks to infer information from the price means that the stock price is different from the price of fish: the fishmonger's customers do not care that the market price reflects the marginal utilities of other consumers and the marginal costs of fishing. They need only compare the price to their own marginal valuation (see Hayek (1945)). In other words, the fish market is analogous to what is termed a "private values" model in the theory of auctions. By contrast, stock markets concern essentially "common value" models.

In a setting where consumers learn about product quality from the price, both effects may be present: consumers will first infer the quality from the price, then compare the price to their marginal valuation. Models of Rational Expectations Equilibrium (REE) capture both of these effects in general. At one extreme, in the fishmonger example, prices have a direct allocative role and no indirect signaling role. When consumers buy fish it is important that the price reflects information, but the consumers care only about the price and 
do not need to infer the information that determined the price. In general, commodity prices may have both a direct allocative role and an indirect signaling role. For example, if consumers receive different private signals about the quality of fish, the price will convey information about quality as well as information about scarcity. In REE, an agent's demand for the fish will depend on the price through this quality inference. We argue that secondary equity prices are at the other extreme to fish prices: they have an indirect signaling role but no direct allocative role.

These two distinctions between fish prices and stock prices mean that shareholders want managers to draw inferences from prices. There are two complications in designing contracts to induce managers to behave this way. First, managers may have private information that is relevant to the investment decision. The implication of this is that shareholders can not provide simple rules to guide investment based on the observed stock price. The second complication is that managers' decisions may have consequences for the longterm performance of the firm after they have retired.

These special features of the stock market raise the question of whether "efficient" stock prices are related to the efficient allocation of resources. In this article we identify two roles for efficient stock prices in enhancing economic efficiency: a forward-looking or prospective role and a backward-looking or retrospective role. Managerial decisions and stock-price formation are linked. This link depends on stock market traders having incentives to produce information and trade profitably on it. We consider a model that integrates the managerial agency problem with a stock market in which information acquisition is costly and prices are partially revealing.

In the stock market, traders are willing to produce information about the expected future profitability of current investment opportunities, and to trade on this information, if managers' investment decisions are guided by the price signals. Since, in this case, the information produced by the informed traders relates to an investment decision that has not yet been taken, we call this the "prospective" role of stock market prices.

Because of the agency problem, managers will not necessarily extract information from stock prices; they must be given appropriate incentives to make good investment decisions. These incentives are linked to the stock market because stock prices can be used to evaluate previous management decisions. Stock prices can then improve investment decisions by allowing more accurate monitoring of the quality of past managerial investment policy. We call this a "retrospective" role for stock market prices.

To summarize, the stock market has an information production role and a monitoring role. The prospective role of stock prices arises because we allow the market to have information that the manager does not already have. This potentially allows the current stock price to be of value in making current investment decisions. If the price goes down, the manager is less likely to invest; if the price goes up, he is more likely to invest. Of course, in equilibrium, the price movement incorporates the fact that the manager's investment will, itself, depend on the price. The retrospective role of providing suitable 
managerial incentives arises because we assume that managers' investment decisions can affect the value of the firm over a horizon that may be significantly longer than their tenure. As a result, compensation cannot be based on the realized returns resulting from their decisions, but if informed traders find it profitable to produce information about future profitability, then compensation may be based on the stock price. If the stock price is informative, such a compensation arrangement can ameliorate some of the affects of managerial discretion that can occur when the manager's objective function is different from those of the outside shareholders.

Our model shows how stock prices can serve to allocate equity capital. This arises in an indirect way: agents infer information about investment decisions from stock prices, even though the stock price is not the "cost of capital" for the investment. However, our model may also have another equilibrium that is not economically efficient. If the stock price is uninformative, the manager may never invest (if the average project is a negative net present value (NPV) investment). Conversely, if the manager never invests, there is no reason for traders to produce information, and stock prices will remain uninformative. We show that this economically inefficient, but price efficient, equilibrium will exist if and only if the average project is negative NPV. This equilibrium exists in addition to the informative one in which stock prices lead to an economically efficient allocation of investment resources.

Since the only function of the stock price is the indirect one of conveying information, the question arises of whether the same information transfer could occur in an alternative institution without the price. Indeed, the two tasks of investment appraisal and monitoring management that stock market information is used for are precisely the functions that banks are supposed to perform in making loans. A large literature identifies the role of banks as information producers and monitors of management, e.g., Diamond (1984) and Boyd and Prescott (1986). We also explore how a bank could replace the stock market in our model. Instead of informed traders making decisions about costly information production and possibly trading on their information, the bank hires loan officers who produce information that can be used for both prospective and retrospective evaluation. The same information is produced as in the stock market economy but it is not transmitted via prices.

There is a large body of research on welfare economics, and an equally large one on efficient markets theory. However, there has been relatively little work linking these two literatures. By and large, welfare economists have not studied corporate control or asset pricing, while efficient-markets researchers have taken for granted that informational efficiency implies economic efficiency. For example, Fama (1976) writes:

An efficient capital market is an important component of a capitalist system ... if the capital market is to function smoothly in allocating resources, prices of securities must be good indicators of value. (p. 133)

In welfare economics, there is a literature on the role of the stock market in the efficient allocation of risk (e.g., Arrow (1953), Diamond (1967), and Hirshleifer 
(1972)), but relatively less work on its role in guiding investment in corporations. However, there are two strands of literature that do link stock prices and investment decisions: $q$-theory in Economics and capital budgeting in Finance.

Tobin's (1969) theory is based on $q$, the ratio of current market value of assets to their cost: if $q>1$, the firm should increase its capital stock. The $q$-theory is related to our model in that current stock prices play a role in determining whether new investment is desirable. As emphasized by Fischer and Merton (1984), "the stock market should be a predictor of the rate of corporate investment" (pp. 84-85). As in our model, rising stock prices cause higher investment. The empirical evidence is consistent with this view: investment in plant and equipment increases following a rise in stock prices in all countries that have been studied. In fact, lagged stock returns outperform $q$ in predicting investment. This is true both at the macroeconomic level and in cross-sections of firms. See Barro (1990), Bosworth (1975), and Welch (1994).

We differ from $q$-theory in two main respects. First, we emphasize that firms are controlled not by owners but by managers. The $q$-theory incorporates the prospective role of stock prices but not the retrospective role. The second difference relates to the distinction between marginal $q$, which is relevant for investment decisions, and average $q$, which can be computed directly from the stock price (see Hayashi (1982)). Because, in our model, the informativeness of prices is endogenous, marginal $q$ can only be computed as part of an equilibrium where agents form beliefs about the decision rules followed by other agents. In particular, stock market prices in our model only contain information about future projects that the market believes will be undertaken; this is because in equilibrium, managers will act on this information and so the informed traders will be able to make trading profits that offset their costs of producing the information. In contrast, $q$-theory takes stock prices, and hence $q$, as given: "In the q model, the origin of the information about new projects is unimportant . . . Indeed, Hayashi's formal model has no private information at all. All investors are equally informed, and the stock price reflects fundamentals. This is all that is needed for a $q$ theory model" (Bresnahan, Milgrom, and Paul (1992), p. 212).

In contrast to $q$-theory, the finance literature typically views the chain of causality differently: the information partition of managers is assumed to be finer than that of agents outside the firm. This precludes the possibility of managers learning from stock prices. For example, Korajczyk, Lucas, and Macdonald (1990) and Lucas and Macdonald (1990) interpret the fact that positive abnormal stock returns (over a 200 -day window) precede a seasoned equity issue as evidence of an adverse selection problem in issuing firms, rather than as evidence that rising stock prices send positive signals to managers. This unidirectional view of the information flow is clear in capital budgeting theory.

Capital budgeting theory is a normative decision rule for evaluating investment projects: expected cash flows are discounted at suitably risk-adjusted rates of return. In principle, expected cash flows should be conditional on all available information, which could include the current and past stock prices. 
While this point is generally understood in the literature, capital budgeting theory does not actually explain where expected future cash flows come from. In practice, it is generally assumed that expected future cash flows are exogenous, implying that capital budgeting has little financial or economic content:

... we consider the investment decisions of firms whose shares are traded in perfect capital markets ... Strictly speaking, such decisions are technological rather than 'financial' problems and so belong to the field of 'production.' For a variety of reasons, however, the general subject of 'capital budgeting' has come to be taught in finance courses ... (Fama and Miller (1972, p. 108)).

In our model, not all relevant information is always known by the manager and, consequently, he can improve his decisions by using the prospective stock price. In other words, the stock market may have information that the manager does not have. The expected cash flows for the project are calculated using the stock price and, hence, are not exogenous.

To summarize, this article presents a view of the firm and the stock market with the following features:

- Information about an individual firm's prospects may flow from the stock market into the firm as well as in the other direction;

- Traders will make the effort to acquire this information only if managers will heed the resulting price signals;

- Firms are run by managers with discretion about the flow of investment capital into and out of the firm;

- Because managers' employment horizons are short compared to the horizons over which their decisions affect the firm, they may need to be motivated by compensation linked to share prices;

- Because the role of stock market prices is to signal information rather than to provide a direct allocative mechanism, other institutions, in particular banks, may be equally effective at producing and transferring the information.

The article proceeds as follows. In Section I we set out the model and discuss the assumptions. In Section II we characterize the economically efficient equilibrium. Section III discusses this equilibrium. In Section IV we discuss the uniqueness of the equilibrium, and Section V develops a bank economy. Section VI concludes.

\section{The Model}

In this section we set out the model and assumptions. We study a multiperiod model of a representative firm in stationary equilibrium. We start with an overview of the model and the equilibrium.

Each period, the firm's shares trade in a stock market in which some agents may undertake costly information acquisition. The share price will therefore tend to reflect this information. Investment decisions are made by a sequence 
of managers. In a period when an investment opportunity arrives, the manager who has to make the investment decision can undertake a costly effort that may yield information about the value of a project. The manager can also infer information from the stock price (if it is informative in equilibrium). Then the investment decision is made. The following period, the manager leaves the firm, but the project returns are not realized until the period after that. As a result of this difference in horizons, executive compensation will be linked to the stock price to induce effort.

Only one project may be undertaken at a time. This means that in any given period, the firm will be in one of two states: either it is able to invest in a new project, or it already has a project underway that was started last period. We call the former state a "prospective" market because stock prices can potentially be used to guide investment decisions. The latter state is "retrospective" because the stock price's forecast of next period's return from the project can be used to evaluate the quality of last period's investment decision. We have designed the model for simplicity to separate the retrospective and prospective roles of stock price information by assuming that a new project cannot be started before any existing project has finished.

In the equilibrium with information production, traders may acquire and trade on information, so that both prospective and retrospective prices will be informative. The compensation contract will then be optimally designed, based on the retrospective price, to induce the manager also to make an effort to produce information about the project value. However, sometimes the manager may make this effort but not receive any information, and in that case he will infer information about the project value from the prospective market price.

We now turn to the details of the model.

\section{A. The Firm}

There is a representative all-equity firm with a single, perfectly divisible, share outstanding. Whenever the firm issues new equity, we assume for simplicity (and without loss of generality) that it simultaneously carries out a reverse stock-split to maintain the total number of shares at one.

\section{B. Projects}

The firm can invest in a project that requires $\$ 1$ of investment. The project does not return any cash flows the following period, but realizes a liquidating value the period after. Only one project can be undertaken at once: the firm cannot invest in a new project until the current one has been completed. (The firm need not necessarily undertake a project, even if there is no existing project in progress.) The decision to invest in a project is public information. The project payoff (which occurs the period after next) is equally likely to be either $H$ or $L(H>L)$. There is no cash flow in the interim period. The random return is not publicly known until it actually arrives, but some agents may be able to discover it privately one or two periods in advance. 
In any given period a firm can be in either one of two states. Either it has no current project and consequently is considering investing in a new project (prospective stock market), or it has a project underway and has no capital budgeting decision to take (retrospective stock market).

\section{Discount rate}

The discount rate is $r$, determined exogenously by an alternative activity in infinitely elastic supply.

\section{Managers}

Each firm is run by a manager who is hired in a competitive labor market. Managers have zero opportunity cost (this assumption is without loss of generality). Although firms are long-lived, managers live for only two periods: they manage the business when young, and consume during retirement. The importance of this assumption is that a manager retires (and actually dies) before any project he initiated has come to fruition.

A manager can be in one of two situations. If the firm has no outstanding project when the manager is hired, then he is a "decision-maker": he will choose whether to invest in the new project. Otherwise, if there is a project underway, he has no decision to take: he is a "caretaker." A caretaker is purely vestigial (since he has no opportunity cost he does not require any compensation), and consequently is ignored in our analysis.

A decision-making manager who must decide whether to invest can choose to try to produce information on the project's value. To do this, he must exert effort that costs $e$. However, this does not guarantee that he actually will receive information: if he makes the effort then with probability $\alpha$ he learns the project payoff.

Clearly, shareholders will have to provide a contract to motivate the manager if they want him to produce this information. Because the manager retires before the project value is realized, the contract cannot condition on the actual project performance. However, a contract linked to the stock price may provide adequate incentives. We will show that such a contract may induce the manager to expend effort to produce a signal about the long-term project and make the correct investment decision.

\section{E. Financing}

A decision-making manager has complete discretion over the investment policy of the firm. Each period the firm may receive a cash flow from past investments which is paid out as a dividend. If an investment is undertaken, the cost is raised in a rights issue (with no transaction costs).

\section{F. The Stock Market}

The firm's stock is traded in a competitive market-making system, as usual in the literature following Kyle (1985) and Glosten and Milgrom (1985). Orders 
may originate from informed traders or liquidity traders. The marketmaker sets price to equal expected present value conditional on the orders received, and meets the net order from an inventory of stock and cash.

\section{G. Liquidity Traders}

In each period the chance of a liquidity trader arriving to trade in the stock market is $1-\pi$; in that event he is equally likely to be buying or selling. The quantity traded in either case is $x$. The following period he reverses this trade.

\section{H. Informed Traders}

Each period, there is one informed trader who decides whether to bear a cost $\delta$ of producing information about the payoff of the project. If he incurs the cost, he learns the true value of the project with probability $\pi$. For simplicity, we assume that this event is perfectly negatively correlated with the arrival of a liquidity trader. In a prospective market, the trader may learn the payoff of the project under evaluation. In a retrospective market, the trader may learn the realization of the project undertaken last period. An informed trader, like a liquidity trader, reverses his trade the following period.

\section{Sequence of Events}

When the stock market opens it will either be the case that a caretaker is being hired while a decision-maker is retiring (a retrospective market), or a decision-maker is being hired and the previous manager is retiring (a prospective market). In the latter case, the previous manager could be either a decision-maker who decided against investing last period, or a caretaker finishing up a project started two periods ago. The sequence of events is as follows.

Prospective market:

- Previous project (if any) liquidates.

- If no previous project, decision-making manager retires and is compensated.

- Proceeds of project liquidation are paid out as a dividend or a rights issue is made to cover the managerial compensation.

- Decision-maker hired. Decides whether to make an effort and, if so, learns project value with probability $\alpha$.

- Prospective stock market trades occur.

- Decision-maker chooses whether to invest $\$ 1$ in the project and, if so, raises $\$ 1$ in a rights issue.

If no investment, then next period the firm returns to the prospective market. If the project was approved then the firm continues to the retrospective market next period:

Retrospective market:

- Decision-maker retires. 
- Caretaker hired.

- Retrospective stock market trades occur.

- Decision-maker compensated based on stock price (using a rights offering).

Next period, go to a prospective market.

\section{J. Exogenous Parameters}

The exogenous parameters of the model are: $H, L, r, e, \alpha, \pi, x$, and $\delta$. We assume that the parameters are such that half the investment opportunities are positive net present value and the other half are negative NPV opportunities. The precise reason for this assumption will become clear later on, but it is intended to restrict attention to parameter values where the equilibrium is more interesting. For example, if all the projects were positive net present value, or all negative net present value, the model would clearly be of limited interest. This is assumption (A1) in Appendix A.

We also require conditions on the parameters that ensure that the cost of information production is not prohibitive. Again, the purpose of this assumption is to restrict attention to the interesting cases. The conditions are given as (A2) and (A3) in Appendix A. Finally, we would like the shareholders of the firm to find that a managerial compensation contract that induces effort by the manager is beneficial. This is ensured by (A.4) of Appendix A.

\section{K. Discussion of Assumptions}

We do not provide a theory of the firm in this article. In other words, we take for granted a number of characteristics of firms including: (i) the projects cannot be unbundled through time as "stand-alone" mini-firms; (ii) there are no owner-managers who can internalize the agency problem; (iii) managers have complete discretion over financing and investment decisions.

If (i) were not true, each project would be financed with a initial public offering and prices would be directly allocative. If (ii) and (iii) were not true, there would be no agency problem in the firm. These three assumptions are important distinguishing characteristics of the modern corporation, and we study their consequences.

In reality managers have extensive discretion over dividend policy, leverage, and new security issues. This gives them discretion over cash flows into and out of the firm. We have modeled this in a simple way by assuming that new investment capital is always raised via an equity rights issue (implicitly, we have also assumed that the issue is sufficiently discounted that its success can be guaranteed). Thus, in our model, an equity issue is effectively a negative dividend.

We have assumed that managers' tenures are shorter than project lives. This implies that managers cannot be compensated and motivated on the basis of the realized return from the project. In other words, in a situation where managers' investment decisions have long-term implications, accounting information is not sufficient to provide adequate managerial incentives. Because stock prices, unlike accounting information, incorporate expected future cash 
flows they can be used to motivate managers if they are sufficiently informative. This is the retrospective role of stock prices.

The structure of the model in which prospective and retrospective markets succeed each other as described above should not be taken literally. This sequencing is only for clarity. Clearly, one could construct a more complicated setting in which the stock price simultaneously provides prospective and retrospective information about multiple projects of varying vintage. The only difference when the price plays both a prospective role and a retrospective role, is that the inference from the price would be considerably more complicated.

We are interested in the welfare properties of informationally efficient market prices and, specifically, in their role in leading to better investment decisions. Ideally, a welfare analysis of the model should be based on the utility function of all agents, including those who trade for liquidity motives. Since our focus is on investment efficiency, and since this does not appear to interact in any essential way with the welfare of the liquidity traders, we have simplified the model by assuming exogenous liquidity trade. Hence the welfare criterion that we are concerned with in this article is the efficiency of investment decisions, or equivalently, the net present value of the firm. (See Hellwig (1980), Diamond and Verrecchia (1981), and Dow and Gorton (1995, 1994a, 1994b) on endogenizing liquidity trade.)

\section{Equilibrium}

In this section we define and construct the equilibrium. An equilibrium is:

(i) A pricing rule for the marketmaker that sets price equal to the asset's expected value conditional on the net order flow;

(ii) An investment policy for the manager which maximizes his expected compensation, given his remuneration contract and given the informativeness of stock prices;

(iii) A compensation contract chosen by the stockholders that induces the manager to maximize the value of the firm;

(iv) An optimal decision by traders on whether to produce information and, if so, a trading rule to maximize expected profits.

We consider only stationary equilibria. The assumptions on the exogenous parameters, discussed above in Section II.J., insure that an equilibrium of the model has the following properties:

1. Informed traders (both prospective and retrospective) choose to produce information;

2. The optimal compensation contract induces the manager to produce information also.

\section{A. Overview of the Equilibrium}

We begin by specifying the manager's possible information sets in equilibrium. The manager may receive information directly and, in addition, the stock 
price on average contains information about the return on the project. The manager may learn that the project is high value $(H)$ or low value $(L)$, or he may receive no signal at all $(N)$. The stock price takes one of two possible values: it may be high to reflect a buy order $(B)$, or it may be low in response to a sell order $(S)$.

So, when a manager decides whether to invest in the project, his information consists of his private information, $N, H$, or $L$, and a price, $B$ or $S$. The possible combinations, their probabilities, and the expected values of the project are as follows:

1. $H B$ or $H S:$ In this case the manager receives information that the project payoff will be $H$. Whether the stock price reflects a buy or a sell adds no further information. The probability of this event is $1 / 2 \alpha$ since the manager becomes informed with probability $\alpha$ and receives the good signal with probability $1 / 2$.

2. NB: The probability of this event is $(1-\alpha) \frac{1}{2}$. The expected payoff depends on the relative likelihood of an informed trader and a liquidity trader. As shown in Appendix B, the expected payoff is: $L(1 / 2)(1-\pi)+$ $H(1 / 2)(1+\pi)$.

3. NS: the probability of this event is also $(1-\alpha) 1 / 2$. The expected payoff of the project is: $L(1 / 2)(1+\pi)+H(1 / 2)(1-\pi)$, as shown in Appendix B.

4. $L B$ or $L S$ : The probability of the event that the manager learns $L$ is: $1 / 2 \alpha$. The project payoff is $L$.

These four possibilities may be viewed as four different projects. The discount rate, $r$, which represents an alternative investment opportunity in infinitely elastic supply determines which of these four projects will be positive net present value (NPV). Clearly, project (1) is the most profitable and so on in decreasing order to project (4), the least profitable. We assume that $r$, and the other exogenous parameters, make the first two projects positive NPV and the other two negative NPV. This is condition (A1) of Appendix A:

$$
1 / 2(1+\pi) H+1 / 2(1-\pi) L>(1+r)^{2}>1 / 2(1-\pi) H+1 / 2(1+\pi) L .
$$

Note that the left-hand inequality is precisely the statement that the expected liquidation value of project (2) exceeds the value of one unit invested in the alternative activity for two periods at rate $r$. The right-hand inequality, similarly, states that project (3) is inferior to investing at rate $r$. Condition (A1) is assumed to make the problem interesting. Clearly, otherwise there would be no need for the manager to make inferences from stock prices since his own information would be sufficient.

Figure 1 describes the marginal product of capital schedule derived by aggregating across the representative firms in the economy. The $y$-axis shows the per-period rate of return. The $x$-axis is the proportion of firms in the economy with projects of each of the four types. The marginal product of capital is derived from the first two types of projects and the alternative investment opportunity. The purpose of our analysis is precisely to construct this marginal 


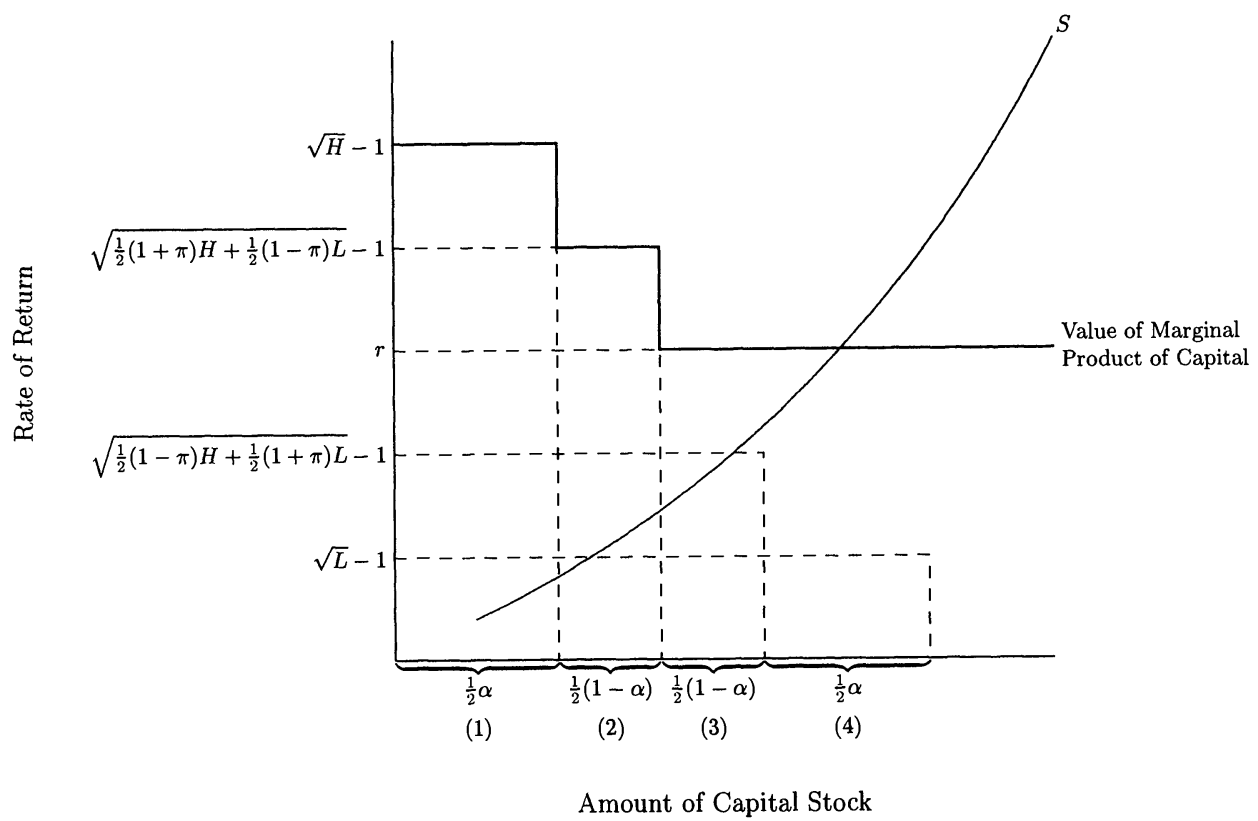

Figure 1. The aggregate supply and demand for capital in an economy with many firms, each with independently and identically distributed projects. The $x$-axis is the proportion of firms in the economy with projects of the four types. The $y$-axis is the per-period rate of return.

product of capital schedule as the equilibrium outcome of an indirect process in which managers with discretion are induced to make inferences from stock market prices to choose investment policies.

We now derive the marketmaker's pricing rule, i.e., that the marketmaker sets price equal to the asset's expected value (discounted at $r$ ) conditional on the net order flow. In both the prospective and the retrospective markets there are generally two possible prices, one for a buy order and one for a sell order, in addition to the unwinding of the previous period's orders. (Note that the unwinding of the previous period's orders is uninformative because it can be perfectly predicted from last period's order flow.) The price has the following general form:

$$
\begin{aligned}
p= & \text { present value of cash flow of current project } \\
& - \text { present value of managerial compensation for current project } \\
& + \text { continuation value of the firm, }
\end{aligned}
$$

where the continuation value $(C V)$ reflects the value of the firm's future positive-NPV projects.

In the prospective stock market there are two possible prices: $p_{B \rightarrow}$ for a buy order and $\mathrm{p}_{\mathrm{S} \rightarrow}$ for a sell order. A buy order could come from either a liquidity trader or an informed trader with favorable information, and the equilibrium 
will reflect the chances of each. Similarly a sell order could be caused by either liquidity trade or unfavorable information.

The possibilities for a retrospective market are more complicated. A retrospective market follows a prospective market in the previous period which had either a high price (buy order) or a low price (sell order). If the project was chosen despite a sell order last period, it is certainly a good project because it must have resulted from the manager receiving favorable information. We call this a "fully revealing" retrospective market. In this case, the marketmaker sets the stock price at

$$
p_{\leftarrow}=\frac{H}{1+r}+\frac{C V}{1+r}-\frac{\text { expected value of manager's compensation }}{1+r} .
$$

Since we have not yet derived the manager's compensation, we cannot complete the derivation of the price at this stage.

The other case occurs when the project was chosen when the stock price was high last period. The manager may or may not have received favorable private information. If he did not receive information, he must have been guided by the stock price, which may or may not have reflected an informed buy order. So the retrospective trader may receive information that is not already publicly known. In this "partially revealing" retrospective market, there are two possible prices: $p_{B \leftarrow}$ for a buy order and $p_{S \leftarrow}$ for a sell order. Again, we cannot solve completely for the prices without first solving for the manager's compensation contract.

\section{B. Computation of Equilibrium}

We first consider the equilibrium conditions (ii): the investment policy for the manager maximizes his expected compensation, given the compensation contract; and (iii): the compensation contract is chosen by the stockholders to induce the manager to maximize the value of the firm. The optimal compensation contract will induce the manager to make an effort to produce information. Compensation may, in general, be contingent on both the prospective and retrospective prices. The possibilities are as follows:

1. The manager invests following a low prospective price and next period the retrospective price is $p_{\leftarrow}$ : payment $m_{1}$;

2. The manager invests following a high prospective price and next period the retrospective price is high: payment $m_{2}$;

3. The manager invests following a high prospective price and next period the retrospective price is low: payment $m_{3}$;

4. The prospective price was low and the manager does not invest: payment $m_{4}$;

5. The prospective price was high and the manager does not invest: payment $m_{5}$.

Proposition 1: The following system of payments constitutes an optimal contract for managerial compensation: $m_{1}=e(1+r) ; m_{2}=2 e /\left(1+\pi^{2}\right) ; m_{3}=0$; $m_{4}=e(1+r) ; m_{5}=e(1+r)(1-\pi) /\left(1+\pi^{2}\right)$. 

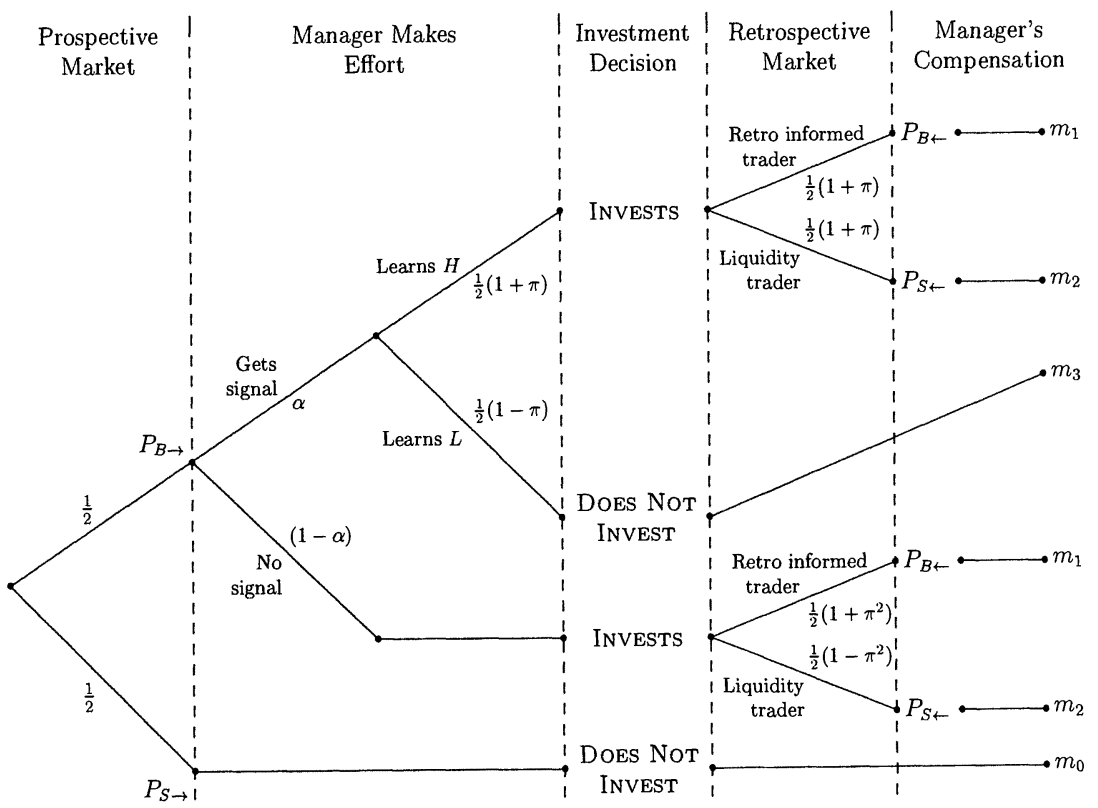

Figure 2. The sequence of events starting in a prospective market. The decision-making manager may see either a buy or sell price in the prospective market. The manager then makes an effort and receives a signal with probability $\alpha$. If a signal is received, it is equally likely to be $H$ or $L$. The tree shows when the decision-making manager will invest. The decision-making manager's compensation depends on which branch of the tree is the outcome of the retrospective market.

Proof: These five numbers must minimize the expected payment by the firm, while satisfying two types of incentive compatibility constraints: first, the manager must be induced to make an effort to produce information (the "effort constraint"); second, he must be induced to take the correct investment decisions (the "investment constraints"). The effort constraint is derived in Step 1; the incentive constraints are given in Steps 2 and 3.

We start by computing the conditional probabilities, given the manager's information, of receiving each of the possible payments. Figure 2 shows how each of these five amounts may arise in equilibrium (the probabilities shown in the figure are derived in Appendix D). From the point of view of the manager, before he has chosen whether to make an effort, the chances of the different payments are as follows:

$m_{1}$ : paid if the prospective price is low $\left(p_{S \rightarrow}\right)$, and the manager gets a good signal $(H)$ and invests; this occurs with probability of: $1 / 2 \alpha^{1 / 2}(1-\pi)$. Similarly, reading off Figure 2 gives the following:

$m_{2}$ : this occurs on two branches of the figure, giving a total probability of:

$$
1 / 8 \alpha(1+\pi)^{2}+1 / 4(1-\alpha)\left(1+\pi^{2}\right)=1 / 2\left(1-1 / 2 \alpha+\alpha \pi-1 / 2 \alpha \pi^{2}+\pi^{2}\right) .
$$


$m_{3}$ : this also occurs on two branches of the figure, giving a total probability of:

$$
1 / 8 \alpha\left(1-\pi^{2}\right)+1 / 4(1-\alpha)\left(1-\pi^{2}\right)=1 / 4(1-1 / 2 \alpha)\left(1-\pi^{2}\right) .
$$

$m_{4}$ : the probability is: $1 / 2(1-1 / 2 \alpha(1-\pi))$.

$m_{5}$ : the probability is: $1 / 4 \alpha(1-\pi)$.

Step 1: The effort constraint is

$$
\begin{gathered}
m_{1} 1 / 4 \alpha(1-\pi)+m_{2}{ }^{1 / 4}\left(1-1 / 2 \alpha+\alpha \pi-1 / 2 \alpha \pi^{2}+\pi^{2}\right)+m_{3} 1 / 4(1-1 / 2 \alpha) \\
\cdot\left(1-\pi^{2}\right)+m_{4}{ }^{1 / 2}(1-1 / 2 \alpha(1-\pi))+m_{5}{ }^{1 / 4} \alpha(1-\pi) \geq e(1+r) .
\end{gathered}
$$

Note that an optimal contract minimizes the expected payment to the manager, hence (1) will hold with equality.

Step 2: We now consider the incentive compatibility conditions for the manager when the prospective market price is low. In this case, we now show that incentive compatibility requires

$$
m_{1}=m_{4} .
$$

To show this note that, by hypothesis, the contract provides incentives so that the manager invests when he receives good news or when he does not receive information but the prospective market price is high. Therefore, the marketmaker who observes that last period the manager invested following a low price must infer that the project is of high value and therefore he sets the price accordingly (a "fully revealing" retrospective market). So, in this event, the contract could in principle condition on whether the investment was undertaken. However, if the investment is undertaken the contract could not also condition on subsequent share price performance since there is only one possible price.

If the contract specifies different payments for investing and not investing, the manager will either always invest or never invest (depending on which payment in larger). This violates the hypothesis that the manager's investment decision depends on his information as well as on the prospective market price.

Step 3: When the prospective market price is high (which, by contrast, will result in a "partially-revealing" retrospective price next period), there are three constraints on the manager's behavior (see Figure 2):

1. He must invest when he receives a good signal:

$$
1 / 2(1+\pi) m_{2}+1 / 2(1-\pi) m_{3} \geq m_{5} .
$$

2. He must not invest when he receives a bad signal:

$$
m_{5} \geq 1 / 2(1-\pi) m_{2}+1 / 2(1+\pi) m_{3} .
$$

3. He must invest if he receives no signal:

$$
1 / 2\left(1+\pi^{2}\right) m_{2}+1 / 2\left(1-\pi^{2}\right) m_{3} \geq m_{5} .
$$


Note that (3) and (4) together imply that $m_{2} \geq m_{3}$, which together with (5) implies that (3) holds strictly and therefore $m_{2}>m_{3}$. This conforms with the economic intuition that the payment scheme must be increasing in the retrospective stock price to induce correct behavior.

The above constraints do not uniquely determine the payments. It is immediate to verify that the payments given in the proposition satisfy constraints (1) to (5), with (1) holding with equality.

We now need to verify that the benefits of this contract to shareholders, in terms of better investment decisions, outweigh the expected compensation cost $(e)$. With this contract, the expected net present value of a potential project net of managerial compensation is

$$
1 / 2 \alpha H /(1+r)^{2}+1 / 2(1-\alpha)[1 / 2(1+\pi) H+1 / 2(1-\pi) L] /(1+r)^{2}-1 / 2-e .
$$

In words, the manager invests half of the time of which with probability $\alpha$ he receives a positive signal and knows the project will pay $H$, and with probability $(1-\alpha)$ he receives no signal and is guided by the prospective price giving a probability $1 / 2(1+\pi)$ of a project worth $H$ and a probability $1 / 2(1-\pi)$ of a project worth $L$.

If the shareholders do not offer the manager compensation for making the effort to produce information, then the manager will simply be guided by the prospective price giving an expected net present value of a potential project of

$$
1 / 2[\pi H+(1-\pi)(1 / 2 H+1 / 2 L)] /(1+r)^{2}-1 / 2 .
$$

Therefore, the shareholders will prefer to induce managerial effort if

$$
e<(H-L) \alpha(1-\pi) / 4(1+r)^{2},
$$

which is assumed to hold by (A.4) of Appendix A. Q.E.D.

Based on the compensation contract we can now determine the equilibrium prices.

Proposition 2 (Equilibrium Prices): The equilibrium prices are given by

$$
\begin{aligned}
p_{B \rightarrow}= & {\left[1-\frac{1}{2} \alpha(1-\pi)\right]\left[-1+\frac{C V}{(1+r)^{2}}\right] } \\
& +\frac{1 / 2 \alpha(1-\pi)\left(C V-\left(e(1+r)(1-\pi) /\left(1+\pi^{2}\right)\right)\right)}{1+r} \\
& -\frac{\left[1 / 2 \alpha(1+\pi) 1 / 2(1+\pi)+(1-\alpha) 1 / 2\left(1+\pi^{2}\right)\right] 2 e}{1+\pi^{2}} \\
& +\frac{1 / 2(1+\pi) H}{(1+r)^{2}}+\frac{[(1-\alpha) 1 / 2(1-\pi)] L}{(1+r)^{2}} ;
\end{aligned}
$$




$$
\begin{aligned}
p_{S \rightarrow}= & \frac{1}{2}(1-\pi) \alpha\left[-1+\frac{\mathrm{H}}{(1+r)^{2}}+\frac{\mathrm{CV}}{(1+r)^{2}}\right] \\
& +[1-1 / 2(1-\pi) \alpha]\left[\frac{C V-e(1+r)}{1+r}\right] ; \\
p_{\leftarrow}= & -e(1+r)+\frac{H}{1+r}+\frac{C V}{1+r} ; \\
p_{B \leftarrow}= & \frac{\left[1 / 2-\pi^{2}-1 / 2 \alpha \pi(1-\pi)\right] /[1-1 / 2 \alpha(1-\pi)](H)}{1+r} \\
& +\frac{\left\{1-\left[1 / 2-\pi^{2}-1 / 2 \alpha \pi(1-\pi)\right] /[1-1 / 2 \alpha(1-\pi)](L)\right.}{1+r} \\
& -\frac{2 e(1+r)}{1+\pi^{2}+\frac{C V}{1+r} ;} \\
p_{S \leftarrow}= & \frac{\{(1-\pi) 1 / 2(1+\pi) /[1-1 / 2(1-\pi) \alpha]\}(H)}{1+r} \\
& +\frac{\{1-(1-\pi) 1 / 2(1+\pi) /[1-1 / 2(1-\pi) \alpha]\}(L)}{1+r}+\frac{C V}{1+r}
\end{aligned}
$$

where

$$
C V=\frac{\begin{array}{c}
-1 / 2-e+1 / 4 H[(1+\pi)+\alpha(1-\pi)] \\
\div(1+r)^{2}+1 / 4 L\left[(1-\pi)(1-\alpha) /(1+r)^{2}\right]
\end{array}}{\left[1-1 / 2 /(1+r)-1 / 2 /(1+r)^{2}\right]}
$$

Proof: These prices are derived in Appendix B and CV is derived in Appendix C. Q.E.D.

We now consider the final condition for equilibrium, i.e., (iv): an optimal decision by traders on whether to produce information and, if so, a trading rule to maximize expected profits. Since information is costly to produce, trading profits must be at least enough to cover this cost.

Proposition 3 (Traders' Optimal Decisions): Traders choose to produce information.

Proof: See Appendix E.

This completes the derivation of the equilibrium. 


\section{Discussion of the Equilibrium}

\section{A. The Prospective and Retrospective Roles of Stock Prices}

We have identified two roles for stock prices in the allocation of investment capital. First, the prospective role is to provide information to the manager. If there is relevant information for the investment decision that is not already contained within the firm, then in equilibrium the manager will use stock prices to help make the investment decision and stock prices will themselves reflect this. Second, the retrospective role for stock prices allows managerial compensation contracts to be linked to performance. When managers investment decisions have long-term implications beyond their career horizons, and when the manager has discretion over project choice, then the stock price is a verifiable predictor of the project's eventual outcome.

Consider first the prospective role of stock prices. In the equilibrium of the model, stock prices convey information to managers that they use to allocate investment capital. Thus, the demand for investment capital (the value of the marginal product of capital curve) itself depends on the role of prices in equilibrium. The marginal product of capital is determined by the role of stock prices, in equilibrium, in improving investment decisions. In other words, the value of the marginal product of capital is not simply a description of the available production technology. Standard neoclassical theory (e.g., $q$-theory) takes the marginal product of capital as a technologically-determined amount. We emphasize that the relevant technology describes not only a description of the firm's production possibilities but also a description of the available technology for producing and transmitting information in the stock market. Furthermore, the value of the marginal product depends not only on the available technology for transmitting information via the stock market. The marginal product of capital curve is determined as part of the equilibrium. It depends on how that informational technology is actually used in equilibrium.

This point is illustrated in Figure 1. The figure represents the aggregate supply and demand for capital in an economy populated by many firms of the type described in our model, each with independently and identically distributed projects. The quantity of capital on the abscissa is expressed per firm in a prospective market situation. The ordinate measures the internal rate of return per period (IRR) on the various project types. The most profitable projects correspond to the case where the manager learns that the value of the project is $H$, in which case the IRR is $(H)^{1 / 2}-1$. The fraction of firms where this occurs is $1 / 2 \alpha$. The next most profitable projects occur when the manager does not receive a signal, but the prospective stock price reflects a buy order. The IRR is $[1 / 2(1+\pi) H+1 / 2(1-\pi) L]^{1 / 2}-1$. A fraction $1 / 2(1-\alpha)$ of firms are in this situation. By assumption (A.1) the preceding two cases are the only positive net present value projects. Next, a fraction $1 / 2(1-\alpha)$ of firms have a low prospective stock price, and the manager did not receive a signal. The IRR is $[1 / 2(1-\pi) H+1 / 2(1+\pi) L]^{1 / 2}-1<r$. Finally, in a fraction $1 / 2 \alpha$ of the firms, the manager receives information that the project payoff would be $L$ and the IRR is $(L)^{1 / 2}-1<r$. Hence, the marginal product of capital curve is not 
exogenous, but rather depends on the equilibrium process whereby prices aggregate information.

We now turn to further discussion of the retrospective role of stock prices. This role concerns managerial discretion and its control by outside shareholders. Managerial discretion in this model is particularly important because the manager determines not only the investment decision, but also the financing of the firm. In our model, as in reality, he chooses how much cash flows in and out of the firm. In other words, the capital markets' evaluation of the firm's project and of any new securities issued to finance the project do not discipline the manager. To see this, contrast the situation of an ongoing firm with that of a new firm engaging in an initial public offering of stock (IPO). The amount of cash raised by the IPO firm depends directly on the capital market's valuation of the firm's project. The price at which the securities are sold regulates the flow of cash into the firm, much like the Hayek-prices at the fishmonger discussed in the Introduction. If the market does not view the project as productive, it will be impossible for the firm to raise the capital in the IPO. The offer will be undersubscribed or cancelled by the underwriters. In an ongoing firm, however, the manager can always raise capital by selling securities that are ultimately backed by the assets-in-place of the firm (the continuation value of the firm in our model). In reality, this can arise by diluting the existing shareholders by selling new equity at lower prices than the current market price, or by selling debt and other securities to new investors. It can also arise, as in our model, by forcing the existing shareholders to contribute capital via a rights issue or a reduced dividend.

The fact that managers have discretion leads to the retrospective role for the stock price. Managerial discretion can be controlled by outside shareholders through a compensation contract that links pay to performance via the stock price. Note, however, that the stock price used for rewarding the manager is, itself, a forecast of the eventual outcome of the manager's project choice. Because the project has long-term consequences, while the manager's tenure at the firm is short, it is impossible to compensate the manager based on the project's actual return. Although we have modeled the retrospective role as involving compensation contracts, it could arise through a takeover market.

\section{B. Related Literature}

There is a large literature on managerial compensation and the role of stock prices that we have called the retrospective role. Kihlstrom and Matthews (1990), for example, provide a sophisticated extension of Leland and Pyle (1977) in which they focus on the retrospective role: an entrepreneur who must make an unobservable costly effort to manage the firm sells part of his equity to outsiders. How much equity he retains determines his incentives for undertaking effort, and this is priced correctly in equilibrium. The equity share that he retains may be interpreted as a compensation contract. Holmstrom and Tirole (1993) argue that a firm's ownership structure influences the extent to which the stock price can retrospectively evaluate managers' decisions because 
of liquidity considerations. Paul (1992) points out that the stock price is the sum of individual values of the firm's component projects and therefore may not be an efficient aggregator of these individual values for optimally determining managerial incentives. For a survey of the literature on the role of stock prices and managerial compensation, see Grant, King, and Polak (1996).

Several articles have considered the prospective role of stock prices. Bresnahan, Milgrom, and Paul (1992) provide a model for the retrospective role of stock prices, but also include a separate discussion of the prospective role of stock prices. However, they do not discuss the feedback effect of investment decisions, guided by prospective prices, on the simultaneous determination of those same prices, in equilibrium: "We assume ... that there are no tricky gaming issues between management and the outsider traders. Suppose, for example, that the manager will withdraw the project if the stock market reaction is adequately adverse. Then the value of the security reflects this prospect ..." (p. 213, footnote 16). This feedback effect is considered by, among others, Henrotte (1992) who provides an explicit model of the prospective role of prices, but does not include any retrospective role. In his model an owneroperated firm adjusts its production level depending on its own internal information as well as other information inferred from the forward price of the commodity produced by the firm. (The price in his model is a commodity forward price rather than the price of the firm's equity.) Leland (1992) also considers the affect of the share price on investment, although the feedback effect is generated by a transaction cost rather than an explicit inference from the price. Dow and Rahi (1996) compute equilibrium in an REE model that incorporates the feedback effects. Other related articles include Fishman and Hagerty (1992) and Leland (1978).

We study a model with both the prospective and retrospective roles. This allows us to see how they are interdependent. In particular, the prospective role explicitly incorporates the feedback effect of the prospective price on the manager's decisions. The retrospective role is explicitly modeled as a chain of short-term stock market traders. Having a model with these ingredients allows us to study the relationship between economic efficiency and stock price efficiency. In the equilibrium constructed above, all agents produce information so that economic efficiency depended on price efficiency. We now turn to examining this more closely by analyzing whether a stock market necessarily implements this allocation of investment resources and whether an alternative institution would also be able to implement this allocation.

\section{Uniqueness of the Equilibrium}

There are three groups of agents who have the potential to produce information: prospective traders, retrospective traders, and managers. There are, therefore, $2^{3}=8$ possible combinations of the information production decisions (ignoring the possibility of mixed strategies). We have shown that there exists an equilibrium where all three classes of agent produce information (under the assumptions on the exogenous parameters given in Appendix A). Given that 
characteristic, the equilibrium is uniquely determined (except for the inessential nonuniqueness of the managerial compensation contract). Here we investigate the question of whether, for given values of the exogenous parameters, there also exist equilibria in which not all agents produce information. Clearly, such equilibria would lead to lower utilities for the traders, if they do not produce information, and lower firm value. In this subsection we focus on the possibility of only one of the other equilibria, in addition to the one described above. The remaining equilibria are characterized and discussed in Dow and Gorton (1996).

Our main conclusion in this section is that the model may have two equilibria (when the costs of information production are small). One equilibrium is the one we studied above: managers and traders produce information and the stock market serves both to guide investment decisions and to reward managerial performance. Both of these roles of the stock market depend on the efficiency of stock prices. Prospective prices reflect traders' signals and guide investment decisions, while retrospective prices reflect traders' signals and are used to link pay to managerial performance. However, in the other equilibrium nobody produces information; stock prices are constant. This equilibrium is Pareto-inferior and results from coordination failure: in Nash equilibrium traders and managers rewards from information production require other agents to produce information. Individually, however, there is no incentive for an agent to produce information. Nevertheless stock prices are "efficient" in the sense of Roberts (1967). The prices are arbitrage-free given public information, i.e., they are "weak-form" and "semi-strong-form" efficient. They are, indeed, "strong-form efficient," that is, they reflect all of the available information in the economy. However, they do not reflect information that might have been produced had agents known that other agents, themselves, would produce information that they might have produced. Hence, although we have identified the stock market as an efficient resource allocation mechanism, there may exist Pareto-inferior equilibria in which the stock market, while "informationally efficient," fails to perform this role.

We start by showing that when information is relatively inexpensive to produce there will be at most two equilibria in the model.

Proposition 4: For sufficiently small values of e and $\delta$, and maintaining assumption (A.1), the economy has at most two equilibria: one where all three groups of agents produce information; and one where nobody produces information. The latter equilibrium exists if and only if the average project is a negative net present value (NPV) investment.

Proof: We have already shown above that the former equilibrium exists for sufficiently small e and $\delta$ (since this will guarantee conditions (A.2), (A.3), and (A.4)). Now suppose that the average project is a strictly positive NPV investment. Then if no information were produced, the manager would always invest. Hence there would be a benefit for the retrospective trader to produce information and if $\delta$ is small enough, the benefit will outweigh the cost. 
Therefore, it can not be an equilibrium for nobody to produce information when the average project is strictly positive NPV.

Consider the case where the average project is negative NPV. Then if neither the manager nor the traders produce information, the manager will never invest. Now consider whether the shareholders will introduce an incentive contract for the manager to produce information. This is impossible since there is no price variability in the retrospective market for the contract to condition on. So they have no incentive to deviate from the proposed equilibrium. On the other hand, the prospective traders do not have an incentive to deviate either, since the price at which they unwind their trades is not correlated with their information (in fact, the share price is simply zero in all periods). Finally, the retrospective traders have no incentive to produce information since there are no projects undertaken for them to learn about.

If the average project is strictly positive NPV, then in any equilibrium at least some projects will be undertaken. If $\delta$ is sufficiently small, there will be a benefit to the retrospective trader producing information. Given this, if $e$ is sufficiently small, there will also be a benefit to the shareholders in giving the manager an incentive contract to produce information. Finally, given that both the manager and the retrospective trader are producing information, if $\delta$ is sufficiently small, there will also be an incentive for the prospective trader to produce information. On the other hand, if the average project is negative NPV, there are two possibilities: either no projects are undertaken in equilibrium, as discussed above, or some projects are undertaken in equilibrium. In the latter case, the arguments given for the strictly positive NPV case apply. Q.E.D.

When the average project is negative NPV, there are two equilibria that are Pareto-ranked. As discussed above, prices are "efficient" in both equilibria; that is, they reflect all available information (Roberts' (1967) strong-form efficiency). Nevertheless, the equilibrium in which no information is produced is economically inefficient. Thus, the fact that prices are strong-form efficient does not in itself imply economic efficiency.

This distinction is substantive. It may seem that the argument just given depends on the distinction between information that agents have actually received and information that agents could easily receive but chose not to. This line of argument would suggest that our claim that strong-form price efficiency does not imply economic efficiency rests upon a semantic quibble about the definition of strong-form efficiency. It might seem that this difference could be overcome by inventing a "super-strong" notion of efficiency in which prices reflect all the information that agents can produce. However, this notion would be intrinsically unworkable since, in general, economies will contain all kinds of opportunities for agents to produce costly information, but there is no way of knowing in advance whether it would be economically efficient for them to produce this information. To do so would first require an explicit computation of efficient outcomes for organizing the economy. 


\section{A Bank Economy: Internal Versus External Financing}

We have described an economy in which stock prices transfer information about prospective investment opportunities and about past investment decisions. While the stock price cannot serve a direct allocative role, we derived (in Section II) an economically efficient equilibrium in which the stock price indirectly performs the allocative role discussed by Hayek (1945). This could be interpreted as a confirmation that Hayek's insight into the function of the competitive market system remains valid in the case where the economy is based on a secondary stock market for the shares of firms with a separation of ownership and control.

The main purpose of Hayek's argument, however, was that the efficient use of information is impossible in an economy with no markets. Of course, Hayek's argument was principally concerned with product markets, not stock markets. As we have seen above, stock markets are quite different. Nevertheless Hayek's argument as applied to stock markets would suggest that the efficient allocation of investment resources can be achieved by stock markets and cannot be achieved by internal capital markets or by banks (as in Germany's universal banking system). This section of the article explores this issue. We emphasize that our analysis does not address the question of the validity of Hayek's argument as applied to product markets.

As a framework for exploring these issues, we now sketch, for comparison, an economy without a stock market. In this economy investment decisions are made via a financial intermediary under the same information constraints as the above stock market economy. In the bank economy, information is not produced or transmitted in the stock market. Instead, information is transmitted by direct communication between the firm and the provider of capital, i.e., the bank. We compare these two systems.

For concreteness we shall interpret this economy as one where investment decision are intermediated by a bank. However, the important point is that the capital market is internal to the relationship between the firm and the bank. It is not an external capital market, such as a stock market. Internal capital markets also include the processes that allocate investment capital within a firm. Indeed, the bank economy we describe in this section could as easily be thought of as the internal capital market of a firm. Thus, the question we explore is whether such internal markets can also function as efficient systems for allocating investment capital. This question is reminiscent of Chandler's (1977) analysis of internal resource allocation within firms replacing external markets: “. . . modern business enterprise took the place of market mechanisms in coordinating the activities of the economy and allocating its resources. In many sectors of the economy, the visible hand of management replaced what Adam Smith referred to as the invisible hand of market forces" (p. 1).

In the bank economy, investment decisions are made by managers as before and information is produced by bank employees rather than traders. These loan officers, like our stock market traders, may receive information if they 
make a costly effort and in equilibrium they will need to be given the correct incentives to do so. Liquidity traders borrow from or deposit in the bank. Finally, the long-term shareholders, previously viewed as the marketmaker, own the firm. The role of the bank is to provide evaluations of possible investments and of managerial performance in regard to past investment decisions. In other words, the bank produces both prospective and retrospective information.

We illustrate that the allocation of equity capital in the bank economy could, in principle, be just as efficient as in the stock market economy. The allocation of equity capital in the stock market economy is second best because stock prices are noisy. Therefore, a manager who is guided by the stock price may make an incorrect investment (given the trader's information). In this economy however, liquidity trade is necessary to allow informed traders to make enough profits to cover the cost of information production.

The bank economy is also in a second best world. The bank produces and transfers both prospective and retrospective information to the firm. Because the bank faces an agency problem in hiring "loan officers" to produce information, noise will again be introduced into the information transmission process. In the stock market case, noise is introduced when decentralized groups, informed traders and liquidity traders, meet in the stock market. In the bank economy, decisions are taken within a large organization, and noise is introduced as a result of agency problems within the organization.

\section{A. The Firm}

The firm faces the same investment opportunities as before. The manager of the firm, as before, may produce information by making an effort. In making his investment decision he can obtain advice from the bank. He retains the authority to invest or not: the bank will be willing to allow this discretion because it recognizes that the manager may have superior information.

The following ownership structures are equivalent: (i) the firm is owned by the long-term shareholders, but they are also willing to deposit funds in the bank at interest $r$; (ii) the bank is owned by the long-term shareholders and the firm is owned by the bank; (iii) any combination of the above.

\section{B. The Bank}

The bank hires agents to produce information about the firm's investment prospects and about the manager's past investment decisions. These "loan officers" have the same possibilities for producing information as the informed traders in the stock market model. Because producing information is costly, the bank must design a compensation scheme that induces them to make the effort.

\section{Liquidity Traders}

The liquidity traders are the same as before, except that instead of buying and selling stock, they deposit or borrow at the bank. 


\section{Loan Officers}

Loan officers play the same role in the bank economy as the informed traders in the stock market economy. In the stock market economy, informed traders traded on the basis of their information. In the bank economy, loan officers will produce a report evaluating an investment. We assume that the loan officers are recruited from a large pool of candidates that consists almost entirely of incompetent agents who are incapable of producing information. Loan officers have limited liability, which prevents them from being penalized for incorrect decisions. However, they can be rewarded for correct decisions. Candidate loan officers, like the informed traders in the stock market may make an effort to produce information. If they do make the effort, they receive information with probability $\pi$. It costs them $\delta$ to make the effort to produce information about the project and they also incur an opportunity cost $k$ that represents their disutility of writing a report within the bank explaining their information. (There is zero disutility of reporting that no signal was received.) They live for two periods: in the first period they work for the bank and in the second period they are rewarded.

If a loan officer produces a report, he will be providing either prospective information or retrospective information. In the former case, he submits a report to the manager and the bank which indicates his view on whether the project being currently considered is of quality $H$ or $L$. In the latter case, he submits a report on a project which was undertaken last period. Again, the report indicates that this project is of quality $H$ or $L$. (In equilibrium, to encourage information production, the bank does not reveal the report of a prospective loan officer to the subsequent retrospective loan officer.)

\section{E. Equilibrium in the Bank Economy}

An equilibrium in the bank economy is: (i) a compensation contract for the manager that maximizes shareholder value; (ii) an investment policy for the manager that maximizes his remuneration under this contract; (iii) a compensation contract for the loan officers that maximizes bank shareholder value; and (iv) a reporting strategy for the loan officers that maximizes their remuneration under this contract. The first two parts, (i) and (ii), are identical to the efficient stock market equilibrium, so we concentrate on the design of the loan officers' contract and their reporting strategy.

Since the bank cannot observe whether a loan officer has made an effort, a contract must be designed to induce effort. The contract will depend on performance: the prospective loan officer is rewarded if his report agrees with the subsequent report of the retrospective loan officer, while the retrospective loan officer is rewarded if his report accurately describes the subsequent project realization. This contract must be designed so as to attract only competent candidates, and to induce them to work to produce information.

The contracting environment here is similar to that in Dow and Gorton (1994b). In that article we study a model of delegated portfolio management in which an investor hires an agent to invest and trade on his behalf. The agent 
can make an effort and receive information with probability $\alpha$, as above. The issue in that article concerns whether, under an optimal contract, the agent trades when he has made an effort but received no information. Since these two contracting environments are similar, for the sake of brevity, we only prove the main result here rather than deriving the full details of the optimal contract.

Proposition 5: In an equilibrium where all agents produce information, the optimal contract will only attract competent loan officers; they will truthfully report the outcome when they do receive a signal; and they will randomly report an outcome otherwise.

Proof: If a contract attracts incompetent loan officers, it will almost surely result in employing an incompetent. Shareholders will not be willing to pay for this: this implies zero payment in case the officer reports that he did not receive a signal (or did not report) since any contract that offers a positive payment for reporting no signal will attract a flood of incompetent loan officers. A competent loan officer who does not make an effort is no better than an incompetent loan officer. Again, principals will not pay for this. Thus the principal offers a contract that only attracts competent loan officers and induces them to work. We now show that they will randomly report project type if they receive no information.

A loan officer agent who made an effort, received no signal, and reports without information must make a strictly positive expected reward, since the payment for reporting information is always nonnegative and sometimes strictly positive (depending on whether it is subsequently corroborated). Therefore if the competent loan officer receives no information, writing a report with a randomly chosen conclusion is a strictly dominant strategy. Q.E.D.

The proposition shows that the internal capital market, i.e., the bank relationship, introduces noise into the economic system via the agency problem with the loan officers. Because of the threat of entry posed by incompetents, the contract cannot offer a payment in the event that the loan officer has, in fact, made an effort, but has received no information. Thus, when a loan officer makes an effort but does not receive information, his best strategy is to randomly report an evaluation. This means that the report will be true with probability $\pi$ and will be randomly chosen with probability $1-\pi$, i.e., the overall probability that a report is correct is $1 / 2(1+\pi)$. Note that this is exactly the same as the probability in the stock market economy that a buy order coincides with a high project value.

The accuracy of the prospective and retrospective evaluations in the bank economy is identical to that of the information in the stock market prices. As a result, the same managerial compensation contract (described in Proposition 1) will apply in the bank economy. So, the allocation of resources in the bank economy is the same as in the stock market economy: the manager will invest if he learns that the project will be high value or if he learns nothing, but the 
bank report on the project is favorable. One period later his compensation is based on the bank's retrospective evaluation of the project.

\section{F. Discussion of the Bank Economy Equilibrium}

In our analysis the allocation of investment resources in the bank economy is the same as in the stock market economy because the "noise trade" in the stock market economy is replaced, in the bank economy, with noise in the agency relationship between loan officers and the bank. In the bank economy there cannot be an inefficient equilibrium (if the average project is negative NPV). The reason is that there is no coordination failure since the bank is hiring the loan officers and designing the managerial compensation contract.

Our comparison between a bank economy and a stock market is clearly simplified and we do not interpret this result literally. However, the comparison makes the point that an alternative institution, such as a bank, may be equally capable of performing the two functions of the stock market that we have identified as providing the link between economic efficiency and financial market efficiency. Many observers have gone further, noting the outstanding economic performance of Japan and Germany and suggesting that is due precisely to the role of banking and internal capital markets rather than of the stock exchange in governing investment decisions. Empirically, Gorton and Schmid (1996), studying German universal banking, argue that a bank relationship does substitute for the stock market.

In our model the two types of economy perform equally well, although clearly, depending on the parameterization chosen, either could be made to outperform the other. We have argued that each of the two economies has its own informational frictions that prevent the first-best allocation from being attained. This poses the question of whether there are significant differences between the bank economy and the stock market economy that are not modeled in our analysis.

An interesting hypothesis is that a bank economy and a stock market economy may be suited for the production of qualitatively different kinds of information. This might arise if the aggregation of many different signals about a project's quality resulted in a different assessment in the two kinds of economies. In particular, if a bank has a strong "corporate culture" that prevents loan officers from imitating the behavior of independent informed traders, then the two economies may end up specializing in different types of projects. This argument has been made by Allen (1993). Of course the notion of a "corporate culture" seems quite similar to what some have argued is a tendency for stock market analysts to "herd."

Another possible difference concerns the number of informed analysts assessing companies in the two economies. A large firm's share price may be followed by two dozen or more stock market analysts. However, by the same token, banks can also employ large numbers of analysts to work on a particular company. It is not clear empirically whether bank employees outnumber or are outnumbered by stock analysts working on the same companies. 
It has been suggested that one disadvantage of internal capital markets is that the agents inside the organization may collude, while markets are relatively collusion-proof. Again, however, a counterargument could be made: agents in stock markets may also have strong incentives to collude, as many notorious episodes confirm.

\section{Concluding Remarks}

We started out by noting that fish prices are different from stock prices. They differ in two ways. First, fish prices have a direct allocative role in that consumers decide how much fish to buy after seeing the price. Secondary market stock prices have no direct allocative role because the suppliers of capital (the shareholders) do not choose how much capital enters and exits the firm each period. Instead this decision is made by managers. The second way in which these prices differ is that the consumers of fish compare the fish price to their private valuation, and then decide how much fish to buy. In other words, fish prices are Hayek prices; that is, the consumer cares only about the level of the price without needing to think about how it is determined. Stock prices are different because financial securities are characterized by a pure common values model. Agents care only about the amount of cash a security will generate in the future and so they want to know as much as possible about other agents' estimates of the future cash flows. Therefore, they attempt to draw inferences from stock prices.

The investment decision of the manager requires making inferences from stock prices. Although the manager has discretion over firm investment and financing decisions, this discretion in itself is easy for the shareholders to control (using a forcing contract based the prospective price, e.g., an instruction to invest only if the price moves above $\$ 32.00$ ). But since managers may also have private information, shareholders cannot simply instruct managers to invest based on the prospective share price. Rather, shareholders must design compensation contracts that indirectly induce the manager to optimally combine private information with inferences drawn from the stock price. The compensation contract is based on the stock price subsequent to the investment decision, linking managerial pay to performance. We analyzed these two roles of share prices. The prospective role concerned the transmission of information from outside the firm to the manager, while the retrospective role provided information about past investment decisions that could be used to motivate the manager to produce information inside the firm.

Because the role of stock prices in the allocation of resources is indirect, the link between economic efficiency and price efficiency is tenuous. We show this in two ways. First, while stock prices are always efficient, agents may not produce information because they believe that stock prices are not informative and this belief is self-fulfilling. In this case, the allocation of investment capital is inefficient, although prices are strong-form efficient. Second, the role of stock prices in the transmission of information can occur without using prices at all. An internal capital market, such as a bank relationship, may perform the same 
roles of information production and performance monitoring as the stock market. While there are many differences between internal and external capital markets, our point is to emphasize that on purely theoretical grounds one cannot conclude that one is superior to the other.

\section{Appendix A}

Conditions on Exogenous Parameters

As explained in section I.J, we require the following conditions on the exogenous parameters:

$$
\begin{gathered}
1 / 2(1+\pi) H+1 / 2(1-\pi) L>(1+r)^{2}>1 / 2(1-\pi) H+1 / 2(1+\pi) L \\
\left.p_{B \rightarrow}-1-1 / 2 /(1+r)\right]+p_{S \rightarrow}[1-1 / 2 /(1+r)]+p_{B \leftarrow} 1 / 2(1+\pi) /(1+r) \\
+p_{S \leftarrow}\left[\frac{1 / 2(1-\pi)}{1+r}-\frac{(1+\pi) e}{(1+r)\left(1+\pi^{2}\right)}+\frac{e(1+r)(1-\pi)}{1+\pi^{2}}\right] \geq 2 \delta / x \pi \\
{\left[\frac{1+\pi}{2-\alpha+\alpha \pi}\right]\left[-p_{B \leftarrow}+\frac{1 / 2 p_{B \rightarrow}}{1+r}+\frac{1 / 2 p_{S \rightarrow}}{1+r}+\frac{H}{1+r}\right]+\left[\frac{(1-\pi)(1-\alpha)}{2-\alpha+\alpha \pi}\right]} \\
\cdot\left[p_{S \leftarrow}-\frac{1 / 2 p_{B \rightarrow}}{1+r}-\frac{1 / 2 p_{S \rightarrow}}{1+r}-\frac{L}{1+r}\right] \geq \delta / x \pi(A) \\
e<\frac{1 / 4(H-L) \alpha(1-\pi)}{(1+r)^{2}}
\end{gathered}
$$

where the prices $p_{B \rightarrow}, p_{S \rightarrow}, p_{B \leftarrow}$ and $p_{S \leftarrow}$ are defined in Section II.D. and formulas expressing them in terms of exogenous parameters are given in Appendices B and C. Since these formulas are quite long we have not substituted for the prices here. The role played by (A.1) is explained in Section II.B. The roles played by (A.2) and (A.3) are explained in Proposition 2.

\section{Appendix B}

Proof of Proposition 2 (Calculation of Stock Prices)

Prospective Stock Market Prices: In the prospective stock market there are two possible prices each period: $p_{B \rightarrow}$ for a buy order and $p_{S \rightarrow}$ for a sell order. In general we will refer to a price reflecting a buy order as a "high price" and a price reflecting a sell order as a "low price."

$p_{B \rightarrow}$ can arise as follows:

- A liquidity trader arrives and buys: this occurs with probability $(1-\pi) 1 / 2$.

- A prospective informed trader arrives and buys. This happens if the trader learns that the current project will succeed. The probability of this event is $\pi \frac{1}{2}$. 
So, the conditional probability that the project, if chosen, would succeed, given that there is a buy order, is

$$
(\pi+1 / 2(1-\pi)) /(\pi+(1-\pi))=\pi+1 / 2(1-\pi)=1 / 2(1+\pi) .
$$

We now compute the price in this event. This depends on the expected payoff that the project would yield in two periods' time. Recall that with probability $\alpha$ the manager receives a signal and will ignore the stock price when making the investment decision. There are therefore three possibilities, with the following probabilities (conditional on a buy order):

1. The project value is $H$ and the manager gets a signal. In this case the project payoff is certain to be $\mathrm{H}$ and the project is chosen so the value of the share is

$-1-\left[1 / 2(1+\pi) m_{2}+1 / 2(1-\pi) m_{3}\right] /(1+r)+H /(1+r)^{2}+C V /(1+r)^{2}$,

where $C V$ is the continuation value of a share in the firm as described and calculated in Appendix B below. The probability of this event is $1 / 2(1+$ $\pi) \alpha$. (See Figure 2.)

2. The manager does not receive a signal. Since the manager follows the stock price in this case, he invests also. The value is

$$
\begin{aligned}
&-1-\left[1 / 2\left(1+\pi^{2}\right) m_{2}+\right.\left.1 / 2\left(1-\pi^{2}\right) m_{3}\right] /(1+r) \\
&+[1 / 2(1+\pi) H+1 / 2(1-\pi) L] /(1+r)^{2}+C V /(1+r)^{2},
\end{aligned}
$$

and the probability of this event is $1-\alpha$.

3. The project value is $L$ and the manager gets a signal. In this case the project pay off is certain to be $L$ and the project is not chosen. The value of the share is

$$
\left[C V-m_{5}\right] /(1+r)
$$

and the probability of occurrence is $1 / 2(1-\pi) \alpha$. (See Figure 2.)

Averaging over these three cases, the stock price set by the marketmaker on a buy order is

$$
\begin{aligned}
p_{B \rightarrow}= & {[1-1 / 2 \alpha(1-\pi)]\left[-1+\frac{C V}{(1+r)^{2}}\right]+\frac{1 / 2 \alpha(1-\pi)\left(C V-m_{5}\right)}{1+r} } \\
& -\frac{\left[1 / 2 \alpha(1+\pi) 1 / 2(1+\pi)+(1-\alpha)^{1 / 2}\left(1+\pi^{2}\right)\right] m_{2}}{1+r} \\
& -\frac{\left[1 / 2 \alpha(1+\pi)^{1 / 2}(1-\pi)+(1-\alpha) 1 / 2\left(1-\pi^{2}\right) m_{3}\right.}{1+r} \\
& +\frac{1 / 2(1+\pi) H}{(1+r)^{2}}+\frac{\left[(1-\alpha)^{1 / 2}(1-\pi)\right] L}{(1+r)^{2}} .
\end{aligned}
$$


We now consider the price in the event of a sell order, $p_{S \rightarrow \text {. In this case, as }}$ shown in Proposition 1, the manager's compensation is always $e(1+r)$. A sell order can arise as follows:

- a liquidity trader arrives and sells, with probability $1 / 2(1-\pi)$.

- a prospective informed trader arrives and sells. This trader will have learned that the long-term project would realize $L$ two periods from now. The probability of this event is $1 / 2 \pi$.

So the conditional probability that the project would realize value $H$ given that there is a sell order is

$$
(1 / 2)(1 / 2)(1-\pi) /(1 / 2 \pi+1 / 2(1-\pi))=1 / 2(1-\pi) .
$$

We now compute the price in this event. There are four possibilities, with the following probabilities (conditional on a sell order):

1. The project value is $H$ and the manager gets a signal. In this case the project payoff is certain to be $H$ and the project is chosen so the value of the share is

$$
-1-e+H /(1+r)^{2}+C V /(1+r)^{2},
$$

where $C V$ is the continuation value of a share in the firm as described and calculated in Appendix $\mathrm{C}$ below. The probability of this event is $1 / 2(1-\pi) \alpha$.

2. The project value is $H$ but the manager does not receive a signal. Since the manager follows the stock price in this case, he does not invest so the value is $(C V-e(1+r)) /(1+r)$. The probability of this event is $1 / 2(1-\pi)(1-\alpha)$.

3. The project value is $L$ and the manager gets a signal. In this case the project payoff is certain to be $L$ and the project is not chosen. The value of the share is $\left(C V-m_{0}\right) /(1+r)$ and the probability of occurrence is $1 / 2(1+\pi) \alpha$.

4. The project value is $L$ but the manager does not receive a signal. Again he does not invest (since he follows the stock price) and the value is $(C V-$ $e(1+r)) /(1+r)$. The probability of this event is $1 / 2(1+\pi)(1-\alpha)$.

Averaging over these four cases, the stock price set by the marketmaker on a sell order is

$$
\begin{aligned}
p_{S \rightarrow}= & 1 / 2(1-\pi) \alpha\left[-1+H /(1+r)^{2}+C V /(1+r)^{2}\right] \\
& +[1-1 / 2(1-\pi) \alpha][(C V-e(1+r)) /(1+r)] .
\end{aligned}
$$

Retrospective Stock Market Prices

In a retrospective market the firm has a project that was initiated last period and will mature next period. If last period's price reflected a sell order (i.e., $p_{S \rightarrow}$ ), then the project could only have been chosen because the manager 
received good news $(H)$. This is the fully revealing retrospective market. In this case, the marketmaker sets the stock price at

$$
p_{\leftarrow}=-e(1+r)+H /(1+r)+C V /(1+r) .
$$

The less degenerate case of a partially revealing retrospective market occurs when last period's price reflected a buy order $\left(p_{B \rightarrow}\right)$. In this partially revealing retrospective stock market there are two possible prices: $p_{B \leftarrow}$ for a buy order and $p_{S \leftarrow}$ for a sell order. Before the marketmaker observes the order flow, his belief that the project is good, based on the fact that there was a buy order last period and that the project was undertaken, is

$\operatorname{Prob}\left(H \mid p_{B \rightarrow} \&\right.$ invest $)=\frac{\operatorname{Prob}\left(H \& p_{B \rightarrow} \& \text { invest }\right)}{\operatorname{Prob}\left(p_{B \rightarrow} \& \text { invest }\right)}=1 / 2(1+\pi) /[1-1 / 2(1-\pi) \alpha]$.

$p_{B \leftarrow}$ can arise as follows:

- A liquidity trader arrives and buys: this occurs with probability $1 / 2(1-\pi)$.

- A retrospective informed trader arrives and buys. This trader will have learned that $H$ will be realized next period. The probability of this event is $1 / 2 \pi$.

So, the conditional probability of a good project if there is a buy order is

$$
\frac{1 / 2(1-\pi) 1 / 2(1+\pi) /[1-1 / 2(1-\pi) \alpha]+1 / 2 \pi(1)}{1 / 2(1-\pi)+1 / 2 \pi}=\frac{1 / 2-\pi^{2}-1 / 2 \alpha \pi(1-\pi)}{1-1 / 2 \alpha(1-\pi)} .
$$

So

$$
\begin{aligned}
p_{B \leftarrow} & =\left[1 / 2-\pi^{2}-1 / 2 \alpha \pi(1-\pi)\right] /[1-1 / 2 \alpha(1-\pi)](H) 1+r \\
& +\frac{\left\{1-\left[1 / 2-\pi^{2}-1 / 2 \alpha \pi(1-\pi)\right] /[1-1 / 2 \alpha(1-\pi)]\right\}(L)}{1+r}-m_{2}+\frac{C V}{1+r} .
\end{aligned}
$$

$p_{S \leftarrow}$ can arise as follows:

- A liquidity trader arrives and sells: this occurs with probability $1 / 2(1-\pi)$.

- A retrospective informed trader arrives and sells. This trader will have learned that $\mathrm{L}$ will be realized next period. The probability of this event is $1 / 2 \pi$.

So, the conditional probability of a good project if there is a sell order is

$$
\frac{1 / 2(1-\pi) 1 / 2(1+\pi) /[1-1 / 2(1-\pi) \alpha]}{1 / 2(1-\pi)+1 / 2 \pi}=\frac{(1-\pi)^{1 / 2}(1+\pi)}{1-1 / 2(1-\pi) \alpha} .
$$


So

$$
\begin{aligned}
p_{S \leftarrow}= & \frac{\{(1-\pi) 1 / 2(1+\pi) /[1-1 / 2(1-\pi) \alpha]\}(H)}{1+r} \\
& +\frac{\{1-(1-\pi) 1 / 2(1+\pi) /[1-1 / 2(1-\pi) \alpha]\}(L)}{1+r}-m_{3}+\frac{C V}{1+r} .
\end{aligned}
$$

The five prices, (B.2), (B.4), (B.5), (B.6), and (B.7) depend on $C V$, which is given in (C.1) in terms of $r$ and the exogenous parameters of the model. Substituting for the $m_{i}$ s from Proposition 1 gives the prices in Proposition 2. Q.E.D.

\section{Appendix C}

\section{Calculation of the Firm's Continuation Value (CV)}

Define the continuation value $(C V)$ of a firm to be its expected value at the beginning of a prospective market, net of the cash flows that the firm is about to pay or receive (i.e., either the managerial compensation to a retiring decision-maker). This definition insures that the continuation value is not dependent on the state of the firm. To calculate the continuation value we use the standard dynamic programming method, i.e., we list the expected cash flows in and out of the firm up to the point where the firm value is once again equal to $C V$. This recursive relationship eventually gives us a formula for $C V$. At a decision-making date (i.e., a prospective market), there are eight possible outcomes (see Figure 2):

1. The prospective price is high, the manager receives a good signal and invests, and the retrospective price next period is also high. This occurs with probability $1 / 2 \alpha^{1 / 2}(1+\pi) 1 / 2(1+\pi)$ and the value in this case is

$$
-1-m_{2} /(1+r)+H /(1+r)^{2}+C V /(1+r)^{2} .
$$

In words, the investment costs $\$ 1.00$ this period. Next period, the current manager will be compensated by an amount $m_{2}$. Two periods hence the project will realize an amount $H$ and the ongoing firm will, once again, be worth $C V$.

2. The prospective price is high, the manager receives a good signal and he invests, but the retrospective price is low. This occurs with probability $1 / 2 \alpha 1 / 2(1+\pi) 1 / 2(1-\pi)$ and the value in this case is

$$
-1-m_{3} /(1+r)+H /(1+r)^{2}+C V /(1+r)^{2} .
$$

3. The prospective price is high, the manager receives a bad signal and he does not invest. This occurs with probability $1 / 2 \alpha 1 / 2(1-\pi)$ and the value is

$$
\left(C V-m_{5}\right) /(1+r)
$$


4. The prospective price is high but the manager does not receive a signal. $\mathrm{He}$ invests nevertheless, and the retrospective price is also high. This occurs with probability $1 / 2(1-\alpha) \frac{1}{2}\left(1+\pi^{2}\right)$ and the value in this case is

$$
\begin{aligned}
-1-m_{2} /(1+r)+\left[1 / 2(1+\pi)^{2} H\right. & \\
& \left.+1 / 2(1-\pi)^{2} L\right] /(1+r)^{2}\left[\left(1+\pi^{2}\right)\right]+C V /(1+r)^{2} .
\end{aligned}
$$

Note that the probability of the project having a high payoff $(H)$ given that both the prospective and the subsequent retrospective prices were high, and given that the manager did not receive a signal, is derived as follows. The joint probability of the project having a high value and the conditioning events occurring is the sum of the probabilities of the following four cases: (i) both prices were caused by informed traders; probability that this occurs, the manager does not receive a signal, and the project is $H$ is: $1 / 2(1-\alpha) \pi^{2}$; (ii) the first price was caused by a liquidity trader and the second price was caused by an informed trader; probability that this occurs, the manager does not receive a signal, and the project is worth $H$ is: $1 / 4(1-\alpha)(1-\pi) \pi$; (iii) the first price was caused by an informed trader and the second price was caused by a liquidity trader; probability that this occurs, the manager does not receive a signal, and the project is worth $H$ is: $1 / 4(1-\alpha) \pi(1-\pi)$; (iv) both prices were caused by liquidity traders; probability of this event, the manager does not receive a signal, and the project is worth $H$ is: $1 / 8(1-\alpha)(1-\pi)^{2}$. The sum of these four probabilities is: $1 / 8(1-\alpha)(1+\pi)^{2}$. The conditional probability is given by Bayes Rule by dividing by $1 / 4(1-\alpha)\left(1+\pi^{2}\right)$, giving $1 / 2(1+\pi)^{2} /\left(1+\pi^{2}\right)$. Similarly, the probability of the project giving a low value $(L)$ conditional on the same events is: $1 / 2(1-\pi)^{2} /\left(1+\pi^{2}\right)$.

5. The prospective price is high but the manager does not receive a signal. He invests nevertheless, and the retrospective price is low. This occurs with probability $1 / 2(1-\alpha) 1 / 2\left(1-\pi^{2}\right)$ and the value in this case is

$$
-1-m_{3} /(1+r)+(1 / 2 H+1 / 2 L) /(1+r)^{2}+C V /(1+r)^{2} .
$$

Note that in this case the project is equally likely to be high or low in value (compare with the previous case).

The following cases correspond to the lowest branch of Figure 2, where the manager receives fixed compensation $e(1+r)$.

6. The prospective price is low, but the manager gets a good signal and invests (the retrospective price is fully revealing). This occurs with probability $1 / 2 \alpha 1 / 2(1-\pi)$. The value is then

$$
-1-e+H /(1+r)^{2}+C V /(1+r)^{2} .
$$

7. The prospective price is low, the manager gets a bad signal, and he does not invest. This occurs with probability $1 / 2 \alpha 1 / 2(1+\pi)$. The value is then

$$
(C V-e(1+r)) /(1+r) .
$$


8. The prospective price is low and the manager receives no signal so he does not invest. This occurs with probability $1 / 2(1-\alpha)$ and value is as in Case 7 . The continuation value of the firm is the expectation of the values in each of these eight events

$$
\begin{aligned}
C V= & 1 / 8 \alpha(1+\pi)^{2}\left[-1-\frac{m_{2}}{1+r}+\frac{H}{(1+r)^{2}}+\frac{C V}{(1+r)^{2}}\right] \\
& +1 / 8 \alpha\left(1-\pi^{2}\right)\left[-1-\frac{m_{3}}{1+r}+\frac{H}{(1+r)^{2}}+\frac{C V}{(1+r)^{2}}\right] \\
& +\frac{1 / 4 \alpha(1-\pi)\left(C V-m_{5}\right)}{1+r} \\
& +1 / 4(1-\alpha)\left(1+\pi^{2}\right)\left[-1-\frac{m_{2}}{1+r}\right. \\
& +1 / 4(1-\alpha)\left(1-\pi^{2}\right)\left[-1-\frac{m_{3}}{1+r}+\frac{1 / 2 H+1 / 2 L}{(1+r)^{2}}+\frac{C V}{(1+r)^{2}}\right] \\
& +1 / 4 \alpha(1-\pi)\left[-1-e+\frac{1 / 2(1+\pi)^{2} H+1 / 2(1-\pi)^{2} L}{(1+r)^{2}}+\frac{C V}{(1+r)^{2}}\right] \\
& +\frac{1 / 4 \alpha(1+\pi)(C V-e(1+r))}{1+r}+\frac{1 / 2(1-\alpha)(C V-e(1+r))}{1+r}
\end{aligned}
$$

Solving for CV gives the solution

$$
C V=\frac{\begin{array}{c}
-1 / 2-e+1 / 4 H[(1+\pi)+\alpha(1-\pi)] \\
\div(1+r)^{2}+1 / 4 L\left[(1-\pi)(1-\alpha) /(1+r)^{2}\right]
\end{array}}{1-1 / 2 /(1+r)-1 / 2 /(1+r)^{2}}
$$

\section{Appendix D}

Conditional Probabilities for Figure 2 and Proposition 1

This appendix gives the conditional probabilities shown in Figure 2 and needed for the proof of Proposition 1. We start by computing the probabilities following a high prospective price $\left(\mathrm{p}_{\mathrm{B} \rightarrow}\right)$. The probability that the manager will 
invest given that he received a signal and that the price in the prospective market was high is

$\operatorname{Prob}\left(H \mid p_{B \rightarrow} \&\right.$ signal $)$

$$
=\frac{\operatorname{Prob}\left(H \& p_{B \rightarrow} \& \text { signal }\right)}{\operatorname{Prob}\left(p_{B \rightarrow} \& \text { signal }\right)}=\frac{\alpha^{1 / 2}\left((1-\pi)^{1 / 2}+\pi\right.}{1 / 2 \alpha}=1 / 2(1+\pi) .
$$

Similarly, the probability that he does not invest in this case is

$$
\operatorname{Prob}\left(L \mid p_{B \rightarrow} \& \text { signal }\right)=1 / 2(1-\pi) .
$$

Following along the top branch of the tree, the probability of a high retrospective price given: a high prospective price, the manager getting a high signal and investing, is

$$
\begin{aligned}
\operatorname{Prob}\left(p_{B \leftarrow} \mid p_{S \rightarrow} \& \text { signal }\right)= & 1 / 2 \operatorname{Prob}(\text { liquidity trader in retrospective market) } \\
& +\operatorname{Prob}(\text { informed trader in retro market) } \\
= & 1 / 2(1-\pi)+\pi=1 / 2(1+\pi) .
\end{aligned}
$$

Similarly, the probability of a low price in the retrospective market, conditional on the same events is $1 / 2(1-\pi)$.

Next, consider the branch of Figure 2 in which a high prospective price is followed by investment, but the manager does not receive a signal. Conditional on this the probability of a high price in the retrospective market is

$\operatorname{Prob}\left(p_{B \leftarrow} \mid p_{B \rightarrow} \&\right.$ signal $)$

$$
\begin{aligned}
= & \operatorname{Prob}\left(p_{B \leftarrow} \& H \mid p_{B \rightarrow} \& \text { no signal }\right)+\operatorname{Prob}\left(p_{B \leftarrow} \& L \mid p_{B \rightarrow} \& \text { no signal }\right) \\
= & \operatorname{Prob}\left(H \mid p_{B \rightarrow} \& \text { no signal }\right) \operatorname{Prob}\left(\left(p_{B \leftarrow} \mid H \& p_{B \rightarrow} \& \text { no signal }\right)\right. \\
& +\operatorname{Prob}\left(L \mid p_{B \rightarrow} \& \text { no signal }\right) \operatorname{Prob}\left(\left(p_{B \leftarrow} \mid L \& p_{B \rightarrow} \& \text { no signal }\right)\right. \\
= & 1 / 2(1+\pi) 1 / 2(1+\pi)+1 / 2(1-\pi)^{1 / 2}(1-\pi)=1 / 2\left(1+\pi^{2}\right) .
\end{aligned}
$$

Similarly,

$\operatorname{Prob}\left(p_{S \leftarrow} \mid p_{B \rightarrow} \&\right.$ no signal $)=1-\operatorname{Prob}\left(p_{B \leftarrow}\left\lfloor p_{B \rightarrow} \&\right.\right.$ no signal $)=1 / 2\left(1-\pi^{2}\right)$.

Now consider the probabilities following a low prospective price in Figure 2. The probability that the manager who receives a signal following a low prospective price will receive a good signal is:

$$
\operatorname{Prob}\left(H \mid p_{S \rightarrow}\right)=1 / 2(1-\pi) .
$$


(This is calculated as (B.3) in Appendix B.) Similarly, the probability he receives a bad signal, conditional on the same events, is $1 / 2(1+\pi)$, i.e., $1-$ $\operatorname{Prob}\left(H \mid p_{S \rightarrow}\right)$.

Finally, the probability that the retrospective market price is high following a low prospective market price and the manager investing after receiving a good signal is: $1 / 2(1+\pi)$. This is because in these circumstances a high retrospective price will always arise if there is an informed trader in the retrospective market and will arise with probability $1 / 2$ if there is a liquidity trader.

\section{Appendix E}

\section{Proof of Proposition 3}

We show that a trader's expected trading profit exceeds the cost of information production in both the prospective and partially-revealing retrospective markets. We consider each in turn.

Step 1: A trader in the prospective market who makes an effort and receives information is equally likely to receive good or bad news. If he receives good news he buys $x$ shares of the stock at price $p_{B \rightarrow}$ and sells them one period later (in the partially-revealing retrospective market) at either $p_{B \leftarrow}$ or $p_{S \leftarrow}$. Since he has received good news, $p_{B \leftarrow}$ is more likely than $p_{S \leftarrow}$ (the probabilities are given in Appendix F). His payoff (per share) is

$$
-p_{B \rightarrow}+\left[1 / 2(1+\pi)\left(p_{B \leftarrow}-m_{2}\right)+1 / 2(1-\pi)\left(p_{S \leftarrow}-m_{3}\right)\right] /(1+r) .
$$

Note that the decision-making manager who retires just before the retrospective market is compensated, reducing the value of the firm.

If the trader receives bad news, he sells $x$ shares short at $p_{S \rightarrow}$ and covers his position by buying the same number of shares one period later. In this case, the manager will not invest as he relies on the price if he receives no signal, while if he does receive a signal it must also be unfavorable. Consequently the market one period later will be a prospective market in which it is equally likely for the price to be $p_{B \rightarrow}$ or $p_{S \rightarrow}$. His payoff per share in this case is

$$
p_{S \rightarrow}-\left(1 / 2 p_{B \rightarrow}+1 / 2 p_{S \rightarrow}-m_{4}\right) /(1+r) .
$$

Since effort costing $\delta$ produces information with probability $\pi$, he makes the effort if

$$
\begin{aligned}
& 1 / 2\left\{-p_{B \rightarrow}+\frac{1 / 2(1+\pi)\left(p_{B \leftarrow}-m_{2}\right)+1 / 2(1-\pi)\left(p_{S \leftarrow}-m_{3}\right)}{1+r}\right\} \\
& +1 / 2\left\{p_{S \rightarrow}-\frac{1 / 2 p_{B \rightarrow}+1 / 2 p_{S \rightarrow}-m_{4}}{1+r}\right\} \geq \frac{\delta}{x \pi},
\end{aligned}
$$


or

$$
\begin{aligned}
\left.p_{B \rightarrow[-1-1 / 2} /(1+r)\right]+ & p_{S \rightarrow}[1-1 / 2 /(1+r)]+\frac{p_{B \leftarrow 1 / 2}(1+\pi)}{1+r} \\
& +p_{S \leftarrow}\left[\frac{1 / 2(1-\pi)}{1+r}-\frac{(1+\pi) e}{1+\pi^{2}}+\frac{e(1+r)(1-\pi)}{1+\pi^{2}}\right] \geq \frac{2 \delta}{x \pi} .
\end{aligned}
$$

By assumption (A.2) in Appendix A, this inequality is satisfied. Note from the solutions for the prices, given in Appendix B, that the prices do not depend on $\delta$ or $x$. Condition (A.2) therefore amounts to assuming that $\delta / x$ is sufficiently small.

Step 2: Traders choose to produce information and participate in the retrospective stock market. As was explained in Section III, above, the retrospective market can be of two types, depending on whether the price in the prospective market last period was high or low. If the price was low, then the project is certain to succeed and the informed trader's information has no value; this is the fully-revealing retrospective market. Alternatively, the price was high, in which case the retrospective trader may receive information that is not already publicly known: a partially-revealing retrospective market. Since there is no reason to produce information if the price is fully revealing, the trader will consider producing information in the partially-revealing retrospective market.

If a trader in the partially revealing retrospective market receives information, it is not equally likely to be good or bad news. If he receives good news he buys $x$ shares of the stock at price $p_{B \leftarrow}$ and sells them one period later (in the prospective market) at either $p_{B \rightarrow}$ or $p_{S \rightarrow \text {. Since the prices next period reflect }}$ information about the next possible project, their distribution is independent of the value of the current project. $p_{B \rightarrow}$ and $p_{S \rightarrow}$ are equally likely and the retrospective informed trader is, therefore, speculating on the cash flows that will arise before the price is set next period.

His payoff (per share) is

$$
-p_{B \leftarrow}+1 / 2 p_{B\lrcorner} J(1+r)+1 / 2 p_{S\lrcorner} /(1+r)+H /(1+r) .
$$

Note that the compensation for the retiring decision-maker manager has already been paid and the compensation for the incoming caretaker manager is zero. $\mathrm{H}$ is the project dividend that will be paid next period. It can be seen from Appendix $\mathrm{F}$ that the probability of receiving good news given that it is a partially revealing retrospective market is

$$
(1+\pi) /(2-\alpha+\alpha \pi) .
$$

If he receives bad news, he sells $x$ shares short at $p_{\mathrm{S} \leftarrow}$ and covers his position by buying the same number of shares one period later. Again, one period later 
there will be a prospective market in which it is equally likely for the price to be $\mathrm{p}_{\mathrm{B} \rightarrow}$ or $\mathrm{p}_{\mathrm{S} \rightarrow}$. His payoff per share in this case is

$$
+p_{S \leftarrow}-1 / 2 p_{B\lrcorner} /(1+r)-1 / 2 p_{S\lrcorner} /(1+r)-L /(1+r),
$$

where the compensation received by the retiring decision-making manager has already been paid and the incoming caretaker will earn zero. $L$ is the dividend that will be paid next period. It can be seen from Appendix $F$ that the probability of receiving bad news given that it is a partially revealing retrospective market is:

$$
(1-\pi)(1-\alpha) /(2-\alpha+\alpha \pi) .
$$

Since effort costing $\delta$ produces information with probability $\pi$, and he trades $x$ shares, he will make the effort if:

$$
\begin{array}{r}
{\left[\frac{1+\pi}{2-\alpha+\alpha \pi}\right]\left[-p_{B \leftarrow}+\frac{1 / 2 p_{B \rightarrow}}{1+r}+\frac{1 / 2 p_{S \rightarrow}}{1+r}+\frac{H}{1+r}\right]+\left[\frac{(1-\pi)(1-\alpha)}{2-\alpha+\alpha \pi}\right]} \\
{\left[p_{S \leftarrow}-\frac{1 / 2 p_{B \rightarrow}}{1+r}-\frac{1 / 2 p_{S \rightarrow}}{1+r}-\frac{L}{1+r}\right] \geq \frac{\delta}{x \pi},}
\end{array}
$$

as we have assumed by (A.3). Note from the solutions for the prices, given in Appendix B, that the prices do not depend on $\delta$ or $x$. Condition (A.3) therefore amounts to saying that $\delta / x$ is sufficiently small. Q.E.D.

\section{Appendix F}

Conditional Probabilities for Proposition 2

This appendix gives the conditional probabilities for the proof of Proposition 2. Although the algebraic derivation of these probabilities is quite long, it is a routine application of Bayes' Rule. We start with the case where the firm is currently in a prospective market (Case A). The probability of a high price in the retrospective market next period given that the project is good is

$\operatorname{Prob}\left(p_{B \leftarrow} \mid H\right)$

$$
\begin{aligned}
& \begin{array}{c}
\operatorname{Prob}\left(p_{B \leftarrow} \text { from an informed trader } \& H\right) \\
+\operatorname{Prob}\left(p_{B \leftarrow} \text { from an uninformed trader } \& H\right)
\end{array} \\
= & \left.\frac{\operatorname{Prob}(\text { informed trader } \& H)+\operatorname{Prob}(\text { uninformed trader } \& H)}{\operatorname{Pa} H}\right) \\
= & {\left[\pi^{1 / 2}+(1-\pi)^{1 / 4}\right] /\left[\pi^{1 / 2}+(1-\pi)^{1 / 2}\right]=1 / 2(1+\pi) . }
\end{aligned}
$$

Similarly,

$$
\operatorname{Prob}\left(p_{S \leftarrow} \mid H\right)=1-\operatorname{Prob}\left(p_{B \leftarrow} \mid H\right)=1 / 2(1-\pi) .
$$




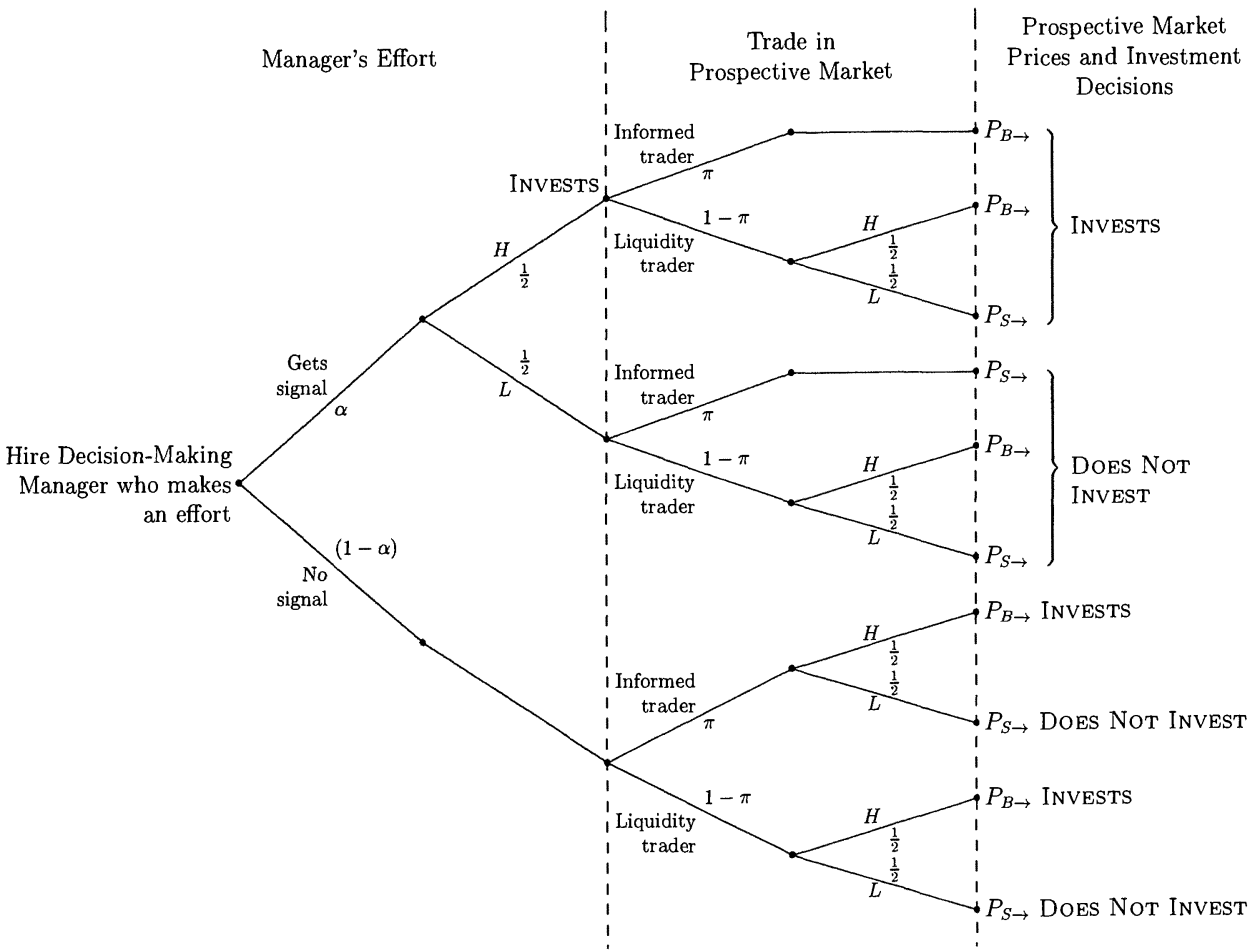

Figure 3. The tree describes the links between a decision-making manager's effort, trade in the prospective market, and the final investment decision. The manager invests if he receives the signal $H$ or if he receives no signal but observes a high price (from a buy order) in the prospective market.

Next consider the firm in a retrospective market (Case B). There are two probabilities that are needed: the probability that the project will succeed given that we are in a partially revealing retrospective market; and the probability that a retrospective market is fully revealing.

The event of the market being retrospective is the same as the event that the investment is undertaken. The joint event of ( $p_{B \rightarrow} \&$ invest) corresponds to a partially revealing retrospective market; the joint event of ( $p_{S \rightarrow} \&$ invest) corresponds to a fully revealing retrospective market.

The probability that the project will succeed given that we are in a partially revealing retrospective market is

$\operatorname{Prob}\left(H \mid p_{B \rightarrow} \&\right.$ invest $=\operatorname{Prob}\left(H \& p_{B \rightarrow} \&\right.$ invest $) / \operatorname{Prob}\left(p_{B \rightarrow} \&\right.$ invest $)$.

$$
\begin{aligned}
\operatorname{Prob}\left(p_{B \rightarrow} \& \text { invest }\right) & =\alpha^{1 / 2} \pi+\alpha^{1 / 2}(1-\pi)^{1 / 2}+(1-\alpha) \pi^{1 / 2}+(1-\alpha)(1-\pi)^{1 / 2} \\
& =1 / 2 \alpha^{1 / 2}(1+\pi)+1 / 2(1-\alpha)=1 / 2-1 / 4 \alpha+1 / 4 \alpha \pi,
\end{aligned}
$$

as can be seen from Figure 3. Similarly, 
$\operatorname{Prob}\left(H \& p_{B \rightarrow} \&\right.$ invest $)=\operatorname{Prob}\left(p_{B \rightarrow} \&\right.$ invest $)-1 / 2(1-\alpha)(1-\pi)^{1 / 2}$

$$
=1 / 2 \alpha^{1 / 2}(1+\pi)+1 / 2(1-\alpha)-1 / 2(1-\alpha)(1-\pi) 1 / 2=1 / 4(1+\pi) .
$$

Hence,

$$
\operatorname{Prob}\left(H \mid p_{B \rightarrow} \& \text { invest }\right)=(1+\pi) /(2-\alpha+\alpha \pi) .
$$

Similarly,

$$
\begin{aligned}
\operatorname{Prob}\left(L \mid p_{B \rightarrow} \& \text { invest }\right) & =1-\operatorname{Prob}\left(H \mid p_{B \rightarrow} \& \text { invest }\right) \\
& =(1-\alpha)(1-\pi) /(2-\alpha+\alpha \pi) .
\end{aligned}
$$

The probability that a retrospective market is fully revealing is given by

$\operatorname{Prob}\left(p_{S \rightarrow} \&\right.$ invest $\mid$ invest $)=\operatorname{Prob}\left(p_{S \rightarrow} \&\right.$ invest $) / \operatorname{Prob}($ invest $)$.

$$
\begin{aligned}
\operatorname{Prob}\left(p_{S \rightarrow} \& \text { invest }\right) & =\alpha^{1 / 2}(1-\pi) 1 / 2=1 / 4 \alpha-1 / 4 \pi \cdot \operatorname{Prob}(\text { invest }) \\
& =\operatorname{Prob}\left(p_{B \rightarrow} \& \text { invest }\right)+\operatorname{Prob}\left(p_{S \rightarrow} \& \text { invest }\right) \\
& =1 / 2-1 / 4 \alpha+1 / 4 \alpha \pi+1 / 4 \alpha-1 / 4 \alpha \pi=1 / 2 .
\end{aligned}
$$

It follows that

$$
\operatorname{Prob}\left(p_{S \rightarrow} \& \text { invest|invest }\right)=1 / 2 \alpha(1-\pi),
$$

and

$$
\operatorname{Prob}\left(p_{B \rightarrow} \& \text { invest } \mid \text { invest }\right)=1-1 / 2 \alpha(1-\pi)=1 / 2(2-\alpha+\alpha \pi) .
$$

\section{REFERENCES}

Allen, Franklin, 1993, Stock markets and resource allocation, in Colin Mayer and Xavier Vives, Eds.: Capital Markets and Financial Intermediation (Cambridge University Press).

Arrow, Kenneth J., 1953, Le role des valeurs boursieres pour la repartition la meilleure des risques, (CNRS, Paris) English translation in Review of Economic Studies (1964) 31, 91-96.

Barro, Robert J., 1990, The stock market and investment, Review of Financial Studies 3, 115-131.

Bosworth, Barry, 1975, The stock market and the economy, Brookings Papers on Economic Activity $2,257-300$.

Boyd, John, and Edward Prescott, 1986, Financial intermediary-coalitions, Journal of Economic Theory 38, 211-232.

Bresnahan, Timothy, Paul Milgrom, and Jonathan Paul, 1992, The real output of the stock exchange, in Zvi Griliches, Ed.: Output Measurement in the Service Sectors (University of Chicago Press).

Chandler, Alfred D., 1977, The Visible Hand: The Managerial Revolution in American Business (Harvard University Press, Cambridge).

Diamond, Douglas, 1984, Financial intermediation and delegated monitoring, Review of Economic Studies 51, 393-414.

Diamond, Douglas, and Robert E. Verrecchia, 1981, Information aggregation in a noisy rational expectations economy, Journal of Financial Economics 9, 221-235. 
Diamond, Peter, 1967, The role of a stock market in a general equilibrium model with technological uncertainty, American Economic Review 57, 759-773.

Dow, James, and Gary Gorton, 1996, Stock market efficiency and economic efficiency: Is there a connection?, Working paper, The Wharton School, University of Pennsylvania.

Dow, James, and Gary Gorton, 1995, Profitable informed trading in a simple general equilibrium model of asset pricing, Journal of Economic Theory 67, 327-369.

Dow, James, and Gary Gorton, 1994a, Arbitrage chains, Journal of Finance 49, 819-849.

Dow, James, and Gary Gorton, 1994b, Noise trade, delegated portfolio management, and economic welfare, Journal of Political Economy, forthcoming.

Dow, James, and Rohit Rahi, 1996, Informed trading, investment, and welfare, Working paper, European University Institute.

Fama, Eugene F., 1976, Foundations of Finance (Basic Books, New York).

Fama, Eugene F., and Merton H. Miller, 1972, The Theory of Finance (Dryden Press, Hinsdale).

Fischer, Stanley, and Robert C. Merton, 1984, Macroeconomics and finance: The role of the stock market, Carnegie-Rochester Conference Series on Public Policy 21, 57-108.

Fishman, Michael, and Kathleen Hagerty, 1992, Insider trading and the efficiency of stock prices, Rand Journal 23, 106-122.

Glosten, Lawrence, and Paul Milgrom, 1985, Bid, ask, and transaction prices in a specialist market with heterogeneously informed traders, Journal of Financial Economics 14, 71-100.

Gorton, Gary, and Frank Schmid, 1996, Universal banking and the performance of German firms, NBER Working paper 5453.

Grant, Simon, Stephen King, and Ben Polak, 1996, Informational externalities, share-price based incentives, and managerial behavior, Journal of Economic Surveys 10, 1-21.

Hayashi, Fumio, 1982, Tobin's marginal and average $q$ : A neoclassical interpretation, Econometrica 50, 213-224.

Hayek, Friedrich A., 1945, The use of knowledge in society, American Economic Review 35.

Hellwig, Martin F., 1980, On the aggregation of information in competitive markets, Journal of Economic Theory 22, 477-498.

Henrotte, Philippe, 1992, Market behavior with endogenous production and asymmetric information, Stanford University, Working paper.

Hirshleifer, J., 1972, The private and social value of information and the reward to inventive activity, American Economic Review 61, 561-574.

Holmstrom, Bengt, and Jean Tirole, 1993, Market liquidity and performance monitoring, Journal of Political Economy 101, 678-709.

Kihlstrom, Richard, and Steven Matthews, 1990, Managerial incentives in an entrepreneurial stock-market model, Journal of Financial Intermediation 1, 57-79.

Korajczyk, Robert A., Deborah J. Lucas, and Robert L. McDonald, 1990, Understanding stock price behavior around the time of equity issues, in R. Glenn Hubbard, Ed.: Asymmetric Information, Corporate Finance and Investment (NBER and University of Chicago Press).

Kyle, Albert S., 1985, Continuous auctions and insider trading, Econometrica 53, 1315-1335.

Leland, Hayne, 1992, Insider trading: Should it be prohibited?, Journal of Political Economy 100, 859-887.

Leland, Hayne, 1978, Information, managerial choice and stockholder unanimity, Review of Economic Studies 45, 527-534.

Leland, Hayne, and David Pyle, 1977, Informational asymmetries, financial structure, and financial intermediation, Journal of Finance 32, 371-387.

Lucas, Deborah J., and Robert L. McDonald, 1990, Equity issues and stock price dynamics, Journal of Finance 45, 1019-1043.

Paul, Jonathan, 1992, On the efficiency of stock-based compensation, Review of Financial Studies $5,471-502$.

Roberts, Harry V., 1967, Statistical versus clinical prediction of the stock market, Working paper, University of Chicago.

Tobin, James, 1969, A general equilibrium approach to monetary theory, Journal of Money, Credit, and Banking 1, 15-29.

Welch, Ivo, 1994, The cross-sectional determinants of corporate capital expenditures: A multinational comparison, Working paper, UCLA. 
http://www.jstor.org

\section{LINKED CITATIONS \\ - Page 1 of 4 -}

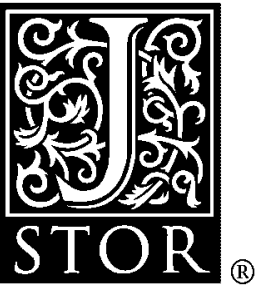

You have printed the following article:

Stock Market Efficiency and Economic Efficiency: Is There a Connection?

James Dow; Gary Gorton

The Journal of Finance, Vol. 52, No. 3, Papers and Proceedings Fifty-Seventh Annual Meeting,

American Finance Association, New Orleans, Louisiana January 4-6, 1997. (Jul., 1997), pp.

1087-1129.

Stable URL:

http://links.jstor.org/sici?sici=0022-1082\%28199707\%2952\%3A3\%3C1087\%3ASMEAEE\%3E2.0.CO\%3B2-\%23

This article references the following linked citations. If you are trying to access articles from an off-campus location, you may be required to first logon via your library web site to access JSTOR. Please visit your library's website or contact a librarian to learn about options for remote access to JSTOR.

\section{References}

The Role of Securities in the Optimal Allocation of Risk-bearing

K. J. Arrow

The Review of Economic Studies, Vol. 31, No. 2. (Apr., 1964), pp. 91-96.

Stable URL:

http://links.jstor.org/sici?sici=0034-6527\%28196404\%2931\%3A2\%3C91\%3ATROSIT\%3E2.0.CO\%3B2-D

\section{The Stock Market and Investment}

Robert J. Barro

The Review of Financial Studies, Vol. 3, No. 1, National Bureau of Economic Research Conference: Stock Market Volatility and the Crash, Dorado Beach, March 16-18, 1989. (1990), pp. 115-131.

Stable URL:

http://links.jstor.org/sici?sici=0893-9454\%281990\%293\%3A1\%3C115\%3ATSMAI\%3E2.0.CO\%3B2-P

\section{The Stock Market and the Economy}

Barry Bosworth; Saul Hymans; Franco Modigliani

Brookings Papers on Economic Activity, Vol. 1975, No. 2. (1975), pp. 257-300.

Stable URL:

http://links.jstor.org/sici?sici=0007-2303\%281975\%291975\%3A2\%3C257\%3ATSMATE\%3E2.0.CO\%3B2-G 
http://www.jstor.org

\section{LINKED CITATIONS}

- Page 2 of 4 -

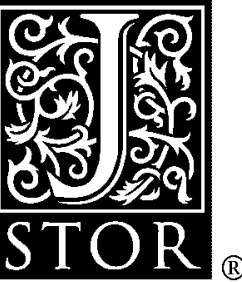

\section{Financial Intermediation and Delegated Monitoring}

Douglas W. Diamond

The Review of Economic Studies, Vol. 51, No. 3. (Jul., 1984), pp. 393-414.

Stable URL:

http://links.jstor.org/sici?sici=0034-6527\%28198407\%2951\%3A3\%3C393\%3AFIADM\%3E2.0.CO\%3B2-1

The Role of a Stock Market in a General Equilibrium Model with Technological Uncertainty Peter A. Diamond

The American Economic Review, Vol. 57, No. 4. (Sep., 1967), pp. 759-776.

Stable URL:

http://links.jstor.org/sici?sici=0002-8282\%28196709\%2957\%3A4\%3C759\%3ATROASM\%3E2.0.CO\%3B2-I

\section{Arbitrage Chains}

James Dow; Gary Gorton

The Journal of Finance, Vol. 49, No. 3, Papers and Proceedings Fifty-Fourth Annual Meeting of the American Finance Association, Boston, Massachusetts, January 3-5, 1994. (Jul., 1994), pp. 819-849. Stable URL:

http://links.jstor.org/sici?sici=0022-1082\%28199407\%2949\%3A3\%3C819\%3AAC\%3E2.0.CO\%3B2-H

\section{Tobin's Marginal q and Average q: A Neoclassical Interpretation}

Fumio Hayashi

Econometrica, Vol. 50, No. 1. (Jan., 1982), pp. 213-224.

Stable URL:

http://links.jstor.org/sici?sici=0012-9682\%28198201\%2950\%3A1\%3C213\%3ATMQAAQ\%3E2.0.CO\%3B2-P

\section{The Use of Knowledge in Society}

F. A. Hayek

The American Economic Review, Vol. 35, No. 4. (Sep., 1945), pp. 519-530.

Stable URL:

http://links.jstor.org/sici?sici=0002-8282\%28194509\%2935\%3A4\%3C519\%3ATUOKIS\%3E2.0.CO\%3B2-1

The Private and Social Value of Information and the Reward to Inventive Activity Jack Hirshleifer

The American Economic Review, Vol. 61, No. 4. (Sep., 1971), pp. 561-574.

Stable URL:

http://links.jstor.org/sici?sici=0002-8282\%28197109\%2961\%3A4\%3C561\%3ATPASVO\%3E2.0.CO\%3B2-2 
http://www.jstor.org

\section{LINKED CITATIONS}

- Page 3 of 4 -

\section{Market Liquidity and Performance Monitoring}

Bengt Holmström; Jean Tirole

The Journal of Political Economy, Vol. 101, No. 4. (Aug., 1993), pp. 678-709.

Stable URL:

http://links.jstor.org/sici?sici=0022-3808\%28199308\%29101\%3A4\%3C678\%3AMLAPM\%3E2.0.CO\%3B2-F

\section{Continuous Auctions and Insider Trading}

Albert S. Kyle

Econometrica, Vol. 53, No. 6. (Nov., 1985), pp. 1315-1335.

Stable URL:

http://links.jstor.org/sici?sici=0012-9682\%28198511\%2953\%3A6\%3C1315\%3ACAAIT\%3E2.0.CO\%3B2-8

\section{Insider Trading: Should It Be Prohibited?}

Hayne E. Leland

The Journal of Political Economy, Vol. 100, No. 4. (Aug., 1992), pp. 859-887.

Stable URL:

http://links.jstor.org/sici?sici=0022-3808\%28199208\%29100\%3A4\%3C859\%3AITSIBP\%3E2.0.CO\%3B2-K

\section{Information, Managerial Choice and Stockholder Unanimity}

Hayne Leland

The Review of Economic Studies, Vol. 45, No. 3. (Oct., 1978), pp. 527-534.

Stable URL:

http://links.jstor.org/sici?sici=0034-6527\%28197810\%2945\%3A3\%3C527\%3AIMCASU\%3E2.0.CO\%3B2-6

\section{Informational Asymmetries, Financial Structure, and Financial Intermediation}

Hayne E. Leland; David H. Pyle

The Journal of Finance, Vol. 32, No. 2, Papers and Proceedings of the Thirty-Fifth Annual Meeting of the American Finance Association, Atlantic City, New Jersey, September 16-18, 1976. (May, 1977), pp. 371-387.

Stable URL:

http://links.jstor.org/sici?sici=0022-1082\%28197705\%2932\%3A2\%3C371\%3AIAFSAF\%3E2.0.CO\%3B2-E

\section{Equity Issues and Stock Price Dynamics}

Deborah J. Lucas; Robert L. McDonald

The Journal of Finance, Vol. 45, No. 4. (Sep., 1990), pp. 1019-1043.

Stable URL:

http://links.jstor.org/sici?sici=0022-1082\%28199009\%2945\%3A4\%3C1019\%3AEIASPD\%3E2.0.CO\%3B2-H 
http://www.jstor.org

\section{LINKED CITATIONS \\ - Page 4 of 4 -}

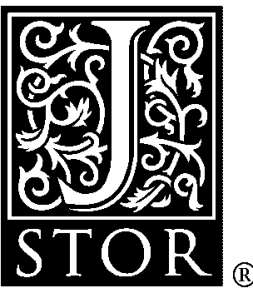

\section{On the Efficiency of Stock-Based Compensation}

Jonathan M. Paul

The Review of Financial Studies, Vol. 5, No. 3. (1992), pp. 471-502.

Stable URL:

http://links.jstor.org/sici?sici=0893-9454\%281992\%295\%3A3\%3C471\%3AOTEOSC\%3E2.0.CO\%3B2-Q

\section{A General Equilibrium Approach To Monetary Theory}

\section{James Tobin}

Journal of Money, Credit and Banking, Vol. 1, No. 1. (Feb., 1969), pp. 15-29.

Stable URL:

http://links.jstor.org/sici?sici=0022-2879\%28196902\%291\%3A1\%3C15\%3AAGEATM\%3E2.0.CO\%3B2-S 